
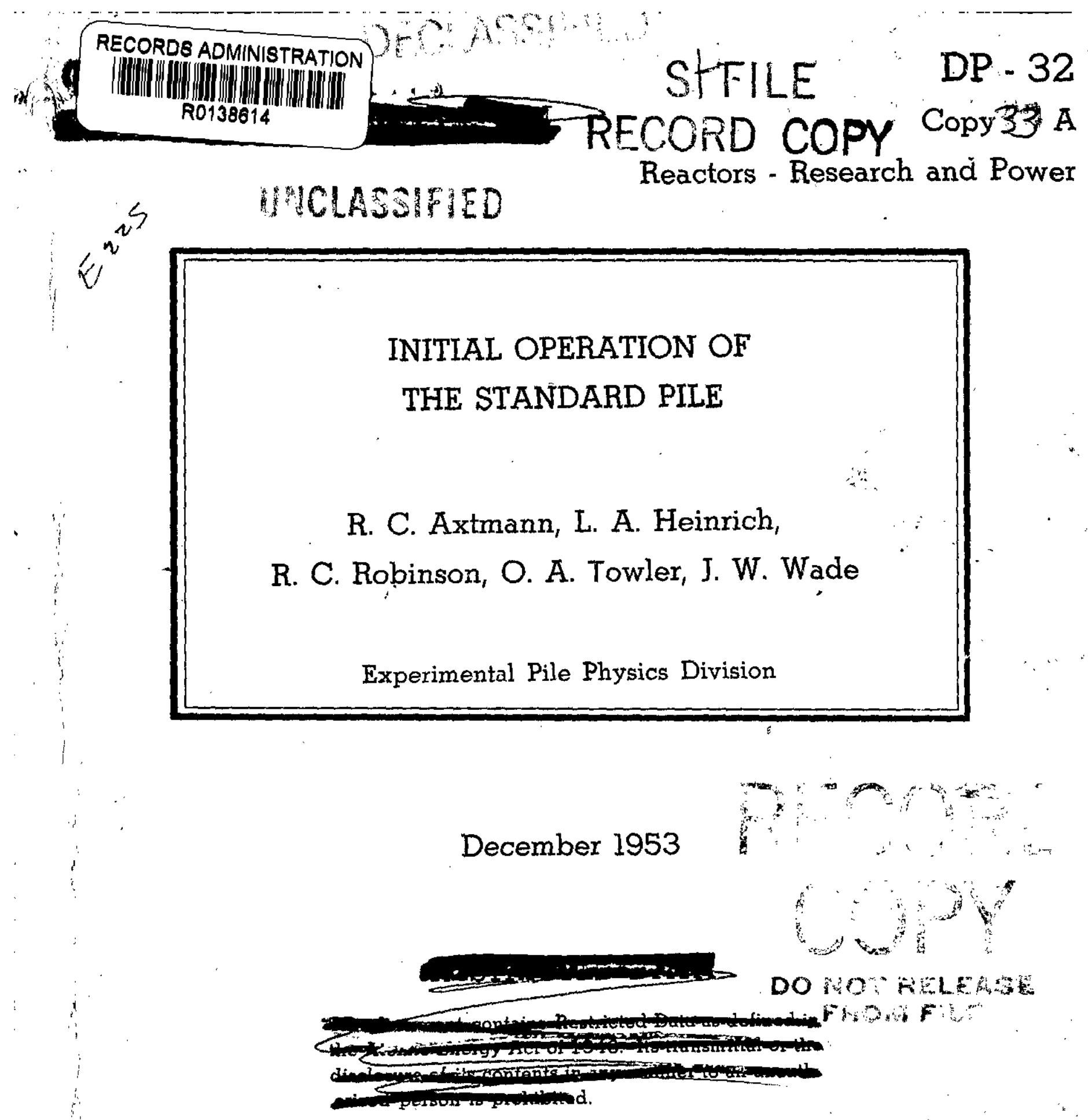

E. I. du Pont de Nemours \& Co., Inc.

Explosives Department - Atomic Energy Division

Technical Division - Savannah River Laboratory

DECLASSIFIED

$\rightarrow \lim _{i}$ 


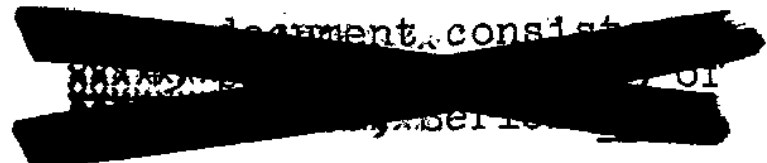

\section{INITIAL OPERATION OF THE STANDARD PILE}

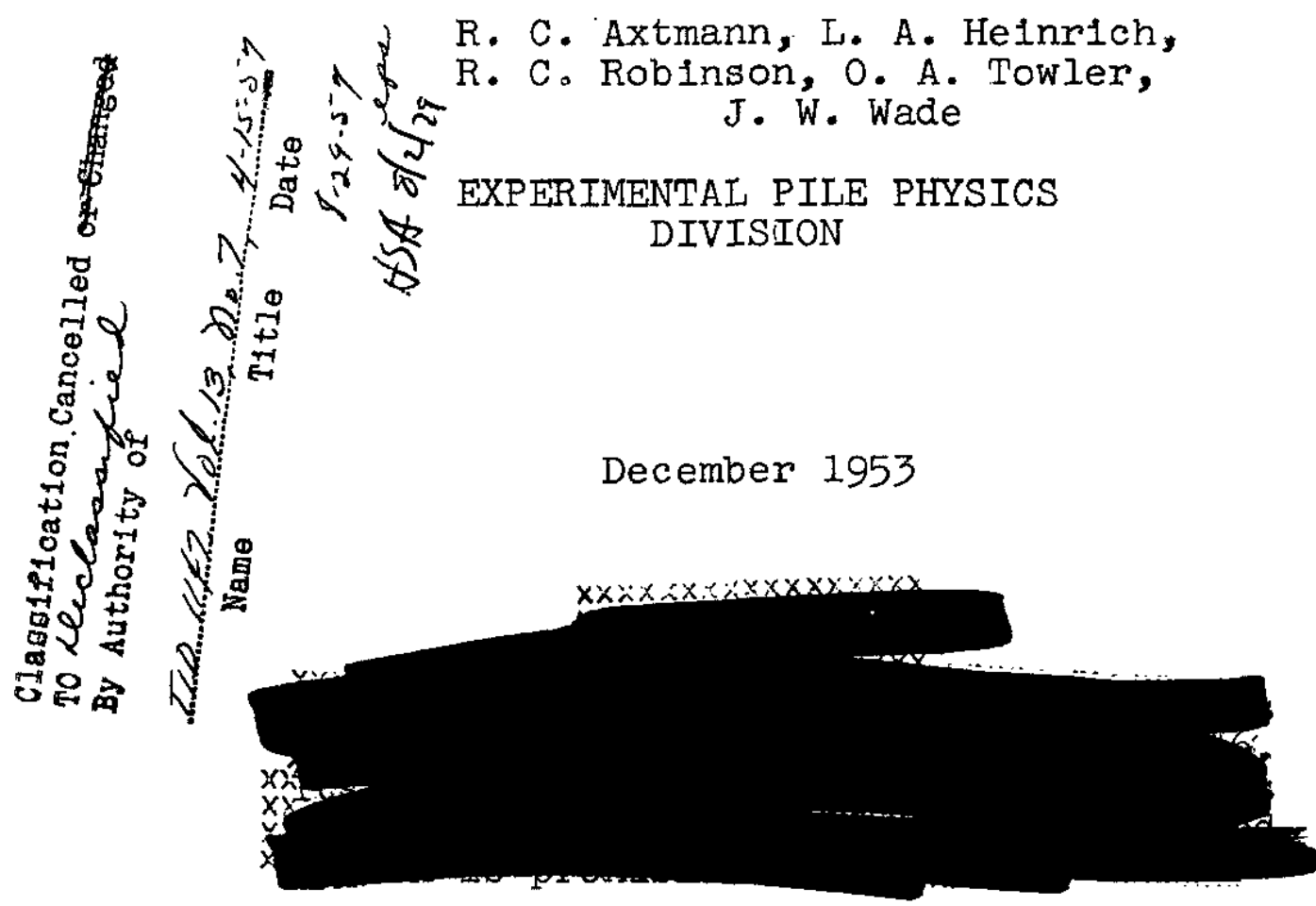

E. I. du Pont de Nemours \& Co.s (Inc.)

Explosives Department - Atomic Energy Division Technical Division - Savannah R1ver Iraboratory

Contract AT(07-2)-1 with the United States Atomic Energy Commission 


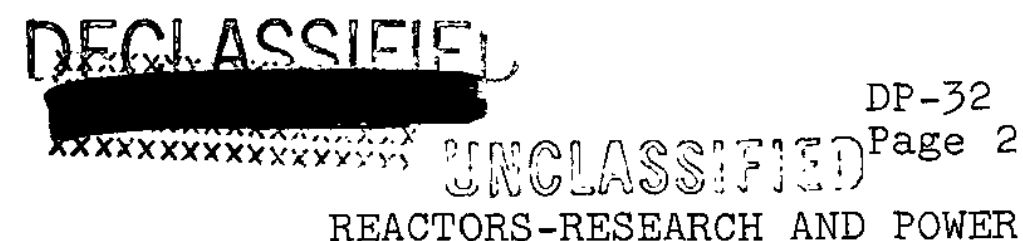

\section{INTERNAL DISTRIBUTION}

1-4. Document Custodian, AEC, SROO, Augusta, Ga.

5. L. Squires - H. Worthington

6. D. F. Babcock

7. W. P. Overbeck

8. A. A. Johnson

9. M. M. Mann

Savannah River Plant

10. M. H. Wahl -

C. W. J. Wende

11-12. G. Dessauer -..777-M File

Savannah River Laboratory

13. J.W. Croach

14-16. R. C. Axtmann - SP File

17. J. I. Crandali - PDP File

18-32. TIS File

33. TIS File Record Copy

34. L. M. Arnett

Argonne National Laboratory

EXTERNAL DISTRIBUTION

35. AF Plant Representative, Burbank

36. AF Plant Representative, Seattle

37. AF Plant Representat1ve, Wood-Ridge

38. ANP Project office, Fort Worth

39-49. Argonne National Laboratory

50. Armed Forces Speclal Weapons Project (Sandia)

51. Armed Forces Special Weapons Project, Washington

52-56. Atomic Energy Commission, Washington

57. Battelle Memorial Institute

58-60: Brookhaven National Laboratory

61. Bureau of Ships 



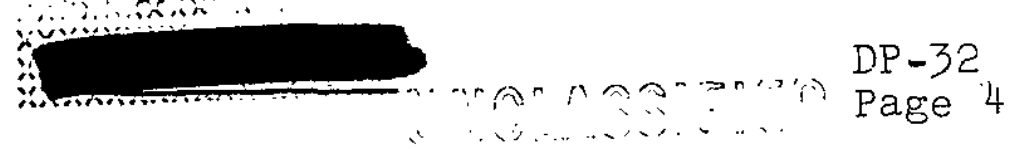

REACTORS-RESEARCH AND POWER

\section{ABSTRACT}

The Standard P1le was first brought to criticality on July 25, 1953. The first two months of operation permitted calibration of the reactor and preparation of it for use as a neutron source in exponential experiments. 


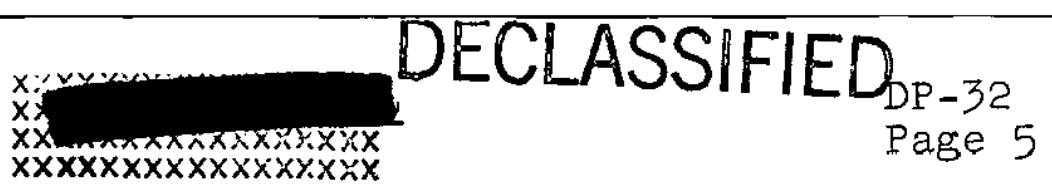

TABLE OF CONTENTS" "ค? $\mathrm{C}$ (ค)

INTRODUCTION

SUMMARY

Loading

Calibration

Flux

Miscellaneous

DISCUSSION

Description of Reactor . . . . . . . . . . 9

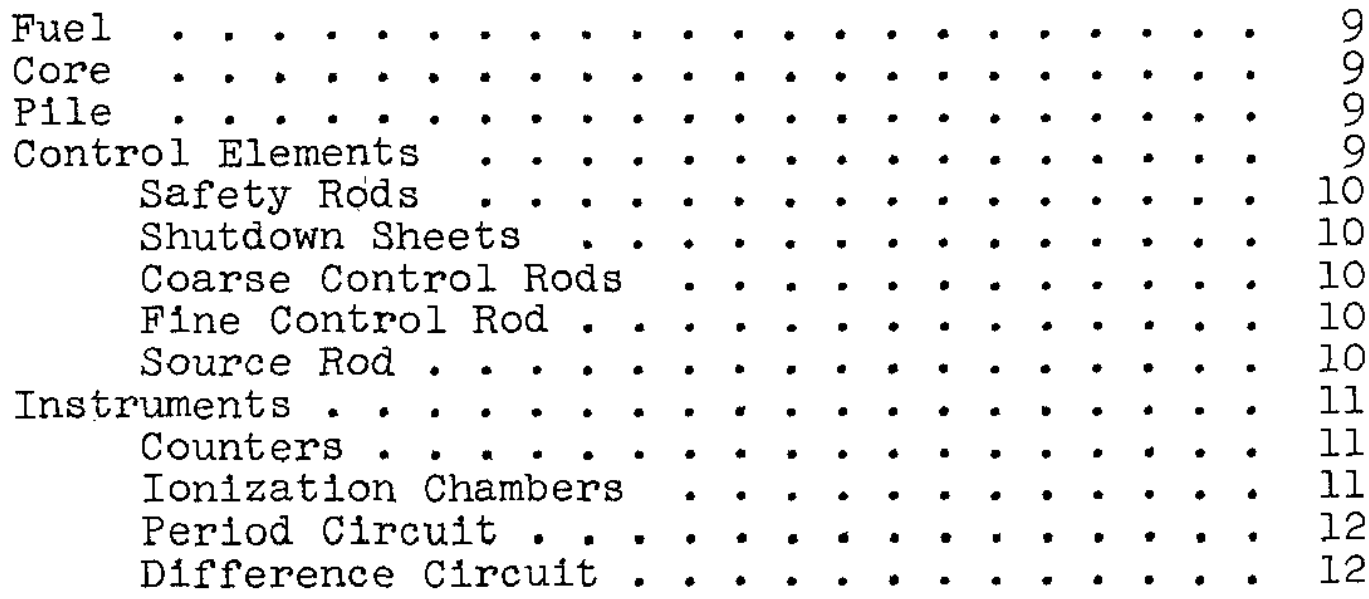

Startup .................. 12

Calibration .................. 14

Coarse Control Rods............. I4

Fine Control Rod .............. 15

Safety Rods................ 17

Rod Drop Method ............ 17

Subcritical Multiplication Method . . . 18

Shut-down Sheet.............. 18

Other Measurements .......... 18

FIux .................... 19

Absolute Flux Calibration ......... 19

Flux Survey of the Exponential Pedestal.... . 19

Miscellaneous Measurements . . . . . . . . 21

Reactivity of a Natural Uranium Slug . . . . . $2 I$ Measurement of Radiation Levels While Operating . 2l.

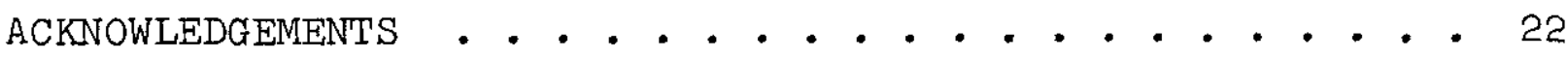

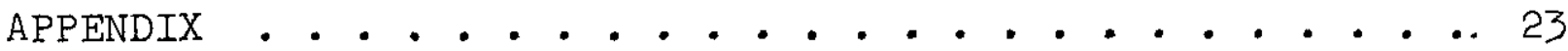


Figure 1 Figure 2 Figure 3 Figure 4 Figure 5 Figure 6 Figure 7 Figure 8 Figure 9 Figure 10 Figure 11 Figure 12

Figure 13 Figure 14 Figure 15

Figure 16

F1gure 17

Figure 18
Standard Pile

Fuel Rod Assembly . . . .. . . . . . . 27

Cross-section of the Reactor Core..... 28

North Side of the Reactor . . . . . . 29

South Side of the Reactor . . . . . . . 30

Control Mechanisms ........... 31

General View Taken From the West . . . 32

Fuel Container . . . . . . . . . . 33

Fuel Storage Vault ......... . . 34

Control Console . . . . . . . . . . 35

Flux Monitoring Instruments . . . . . . 36

Inverse Multiplication vs. Fuel Loading

During Standard Pile Start-up . • • . . 37

Right Coarse Control Rod Calibration. - . 38

East-West Pedestal Flux . . . . . . . 39

Isoflux Plot of the Pedestal Before Addition of Cadmium Rods to the Thermal Column . . . 40 Cadmium Ratio on Pedestal With Thermal

Column ................ 41

Relative Neutron Flux Through Central

Thimble W1th Thermal Column....... 42

Pedestal Flux With Cadmium Rods in Thermal

Column
Table I

Table II

Table III

Table IV

Table V

Table VI
SP Approach to Criticality . • . . . . 13 Keff vs. Number of Fuel Discs... . . . 14 Right Coarse Control Rod Calibration . . . 16 Fine Control Rod Calibration . . . . . 17 Calibration of Safety Rods by Rod Drop

Method Safety Rod Calibration 


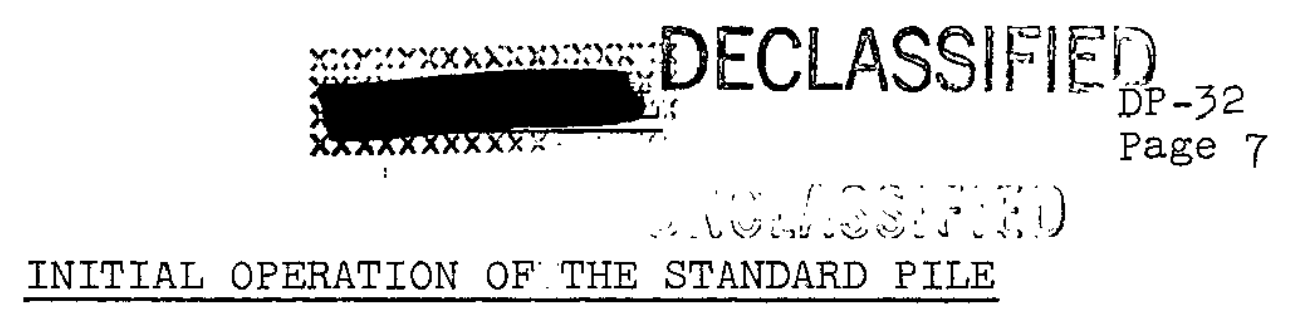

INTRODUCTION

The Standard Pile (SP) is an enriched-uranium, graphitemoderated research reactor located in Building $777-\mathrm{M}$ at the Savannah River Laboratory. It was constructed by the General Electric Company, using the Thermal Test Reactor (TTR) at the Knolis Atomic Power Laboratory as a model and incorporating design improvements suggested by members of both General Electric and du Pont.

The pile attained criticality on July 25, 1953 and was in operation until September 22, 1953. On the latter date, the fuel was unloaded prior to installation of equipment for exponential experiments on top of the reactor.

During the period of initial operation, a variety of experiments aimed at calibrating the reactor and preparing it for use in exponential experiments was performed.

\section{SUMMARY}

LOADING

The critical mass at start-up was $2.54 \mathrm{~kg}$ of $\mathrm{U}^{235}$. Rearrangement of the fuel into a symmetrical pattern gave $2.43 \mathrm{~kg}--$ some 270 grams less than that reported by KAPL for the TTR. Enough extra fuel was added to make $\mathrm{K}_{\mathrm{ef}}=1.0040$. one fue]. disc (5.7 grams of U235) is worth an average of $0.076 \% \Delta \mathrm{K}$ near critical.

\section{CALIBRATION}

The coarse control rods were worth 144 inhours $(0.375 \% \Delta \mathrm{K})$ each, whereas the fine rod controlled 18.8 inhours $(.049 \% \mathrm{~K})$. The safety rods singly gave $0.4 \%$ negative $\Delta \mathrm{K}$; all four together were worth $1.5 \% \Delta \mathrm{K}$. The sixth shutdown sheet was worth $0.9 \% \Delta \mathrm{K}$.

FLUX

Flux measurements made with standardized gold foils at various points in the reactor provided an interim power calibration. The maximum neutron flux in the central thimble during normal operation was about $3 \times 10^{7} \mathrm{n} / \mathrm{cm}^{2} \mathrm{sec}$. This corresponds to a power of approximately one watt. Power levels as high as 30 watts were reached on several occasions.

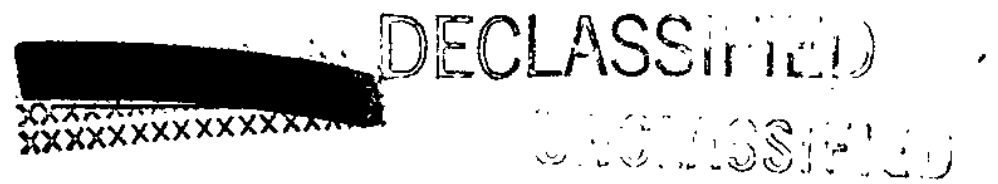


Figure 1 is an isometric drawing of the SP as installed in Building 777-M. The exponential apparatus is not shown in this figure although parts of it appear in the later photographs. The pile is located at one end of a room 16 feet wide, 35 feet long, and 15 feet high. Surrounded by six feet of concrete, the pile room is below ground elevation. Utilities and instmument cables are mu through slots and sleeves which were poured into the concrete shielding walls. There is a room above, separated from the pile room only by an iron grating floor which will be used in conjunction with the exponential experiments. It, too, is surrounded by shielding walls and has a concrete ceiling four feet thick. The control room is adjacent to this room.

Fuel A complete fuel rod assembly is shown in Figure 2 . l'he tuel itself is in the form of discs, about 3 inches in diameter, approximately 0.075 inch thick, with $1 / 2$ inch holes in the center. The discs are a $30 \%$ uranium aluminum alloy containing an average of 5.7 grams of $\mathrm{U}^{235}$ per disc. The alloy is clad with 0.010 inches of aluminum on all sides. The discs are placed on aluminum rods 15 inches long and are separated by aluminum washers. Usually, the discs are evenly spaced over the 15 inches of the rod.

Core As is shown in a cross sectional view in Figure 3 , the reactor fuel container is an annular can 12 inches in inside diameter, 18 inches in outside diameter, and 18 inches long. The annulus accomodates 16 fuel rods and is filled with a high hydrogen content oil (Prorex C). The inside of the annulus is filled with graphite. Graphite around the annulus forms a five foot cube. The fuel is introduced into the container through a loading slot extending in from one side of the reactor. The slot is filled with a graphite plug during pile operation.

Pile There is a 3 -inch diameter removable central graphite thimble, forming the horizontal axis of the fuel container, in which folls and slugs can be inserted for irradiation or calibration. On one side of the graphite cube is a graphite thermal column which forms a 4-foot cube which extends into a shielding wall. Three $4 \times 4 \times 30$-inch graphtte stringers are removable from one side of the reactor. They allow access to the neutron flux just outside the fuel container.

Control'Elements ' The relative position of the various control elements is shown in Figure 3 . All are mounted horlzontally. There are five varieties:

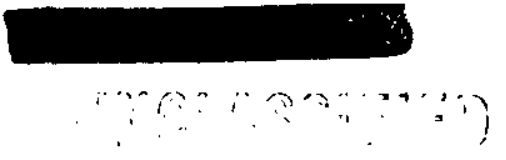




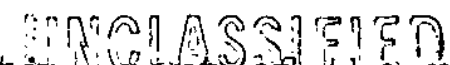

Safety Rods The activelpurt of the rod is a 1/2-inch O. D. cadmium sleeve 0.032 inch thick mounted inside a stainless steel sleeve. The rod is withdrawn by a pneumatically actuated electromagnet. When current to the magnet is stopped, two springs ram the rod into the reactor with an acceleration of approximately $3 \mathrm{~g}$. The four safety rods are cocked whenever the pile is in operation or whenever any loading operation is taking place.

Shutdown Sheets These elements consist of 3-inch wide, .031 inch thick cadmium blades clad with brass and driven by electric motors. Electrical and mechanical interlocks prevent personnel from entering the reactor room unless all six shutdown sheets are in the reactor. The first five shutdown sheets are withdrawn, one at a time, at 2 inches/sec. The sixth shutdown sheet, which must be removed last, has a variable speed motor and a position indicator. Thus, in case a mistake in loading results in the pile going critical on the sixth sheet instead of on the control rods, there is still adequate control available.

Coarse Control Rods These two rods, located $180^{\circ}$ apart, are 0.496 inch cadmium bars clad in stainless steel. They may be removed only in increments of one inch, there being mechanical and electrical interlocks that prevent continuous withdrawal. The actuators for the rods are hydraulic. Specially machined stops located at one-inch intervals on the rods insure reproducibility of the settings to a fraction of a thousandth of an inch.

Fine Control Rod This rod is a $1 / 2$ inch stainless steel sleeve with a wall thickness of 0.065 inch. Actuated by a position demand servo system, the rod may be repositioned with an accuracy and reproducibility better than a thousandth of an inch.

Source Rod A Po-Be neutron source emitting about $10^{6}$ n/sec was triply-canned and placed inside an aluminum rod driven by an electric motor. Interlocks prevent startup of the pile unless the source is in the center. When the pile is shut down or scrammed, the source automatically returns to the center in case it has been withdrawn.

With the exception of the source rod, all of the control elements have active lengths of 16 to 18 inches corresponding roughly to the length of the fuel can. In the cases of the safeties, shutdown sheets and source, the rod is withdrawn all the way out of the

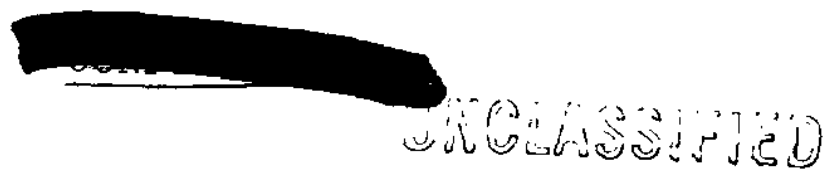




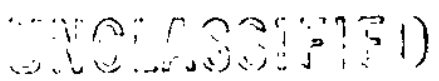

pile, whereas the control rods may just be withdrawn into the reflector.

Figures 4, 5, 6, and 7 give various views of the reactor. Figure 4 , taken from the north side shows the slot down which the fuel is loaded. At the bottom of the slot an assembled fuel rod (Figure 2) is picked up by a revolving reel located inside the annular container which then rotates the fuel out of the way of the slot so that another fuel rod may be plcked up.

Figure 5 shows the south side of the reactor. The small square plate covers the end of one of the removable graphite stringers. On the shelf are some of the ionization chambers used in pile control. The thermal column is not visible in this photograph, but extends through the wall at the right and is accessible from the room beyond.

The various control mechanisms are shown in Figure 6. The pile proper is to the right of them. Figure 7 is a general view of the reactor which shows how the mechanisms extend out the end.

Figure 8 is a view of a spare fuel container. The man in the picture is holding the loading slot and the orientation is similar to that of the diagram of Figure 3 .

A view of the vault in which the enriched fuel is stored when not is use is shown in Figure 9. Twentyfive fuel discs may be stored in each of the wire baskets, the dimensions of which prevent close packing of the fue 1 .

Instruments A Alew of the control console is shown in Figure 10. Some of the monitoring instruments are shown in Figure 11.

Counters Four boron-lined proportional counters located on various sides of the reactor feed pulses to linear amplifiers and thence to scaling circuits. The output of one of the scalers in turn feeds an audioamplifier which gives an audible indication of neutron level. A LiI (TI) scintillation crystal is also used as a counter.

Ionization Chambers Four wide spectrum neutron chambers also located on various sides of the reactor furnish signals to Beckman vibrating reed electrometers. The meters of the electrometers give visual indication of the power level. The electrometers also feed recorders and linear amplifiers. The latter are part of 
a scram system which actuates at approximated $90 \%$ of full scale on the Beckmans.

Period Circuit Operating from the output of a fifth chamber, this circuit contains both a logarithmic amplifier and a period trip circuit which scrams the pile if the e-folding time becomes less than a preset value. The logarithmic amplifier signal goes to a recorder which gives the pile power through six decades.

Difference Circuit In order to amplify small changes In the power level of the pile the current of a neutron sensitive ionization chamber is opposed by a current of adjustable magnitude. Small changes are observed with a vacuum tube voltmeter of high sensitivity.

STARTUP

Before any fuel was loaded, counting rates of all instruments were taken with the source in the center of the reactor. This gave the rates associated with "multiplication one". For each fuel loading, counts were taken with all safety rods, shutdown sheets and control rods in. Counts were then taken with the four safety rods removed, then with the safety rods and shutdown sheets out, and finally with the safeties, shutdown sheets and control rods out of the reactor.

The flrst loading (the A loading) consisted of four fuel rods with 30 evenly spaced fuel discs per rod. The four rods were placed $90^{\circ}$ apart. A multiplication of 1.7 was observed. The B loading consisted of three additional rods, with 30 discs per rod, and resulted in a multiplication of 2.4. Table I gives some of the data taken as criticality was being approached. 
TABLE I. SP APPROACH TO CRITICALITY

\begin{tabular}{|c|c|c|c|c|c|}
\hline $\begin{array}{l}\text { LOADING } \\
\text { IETTER } \\
\end{array}$ & $\begin{array}{l}\text { NO. RODS } \\
\text { ADDED } \\
\end{array}$ & $\begin{array}{l}\text { TOTAL } \\
\text { DISCS } \\
\end{array}$ & $\begin{array}{l}\mathrm{Kg}_{3} \mathrm{OF} \\
\mathrm{U}^{2} 35\end{array}$ & $\begin{array}{l}\text { AVE. INV. } \\
\text { MULT. }\end{array}$ & $\begin{array}{l}\text { AVE. } \\
\text { MULT. }\end{array}$ \\
\hline A & 4 & 120 & .684 & .589 & 1.70 \\
\hline B & 3 & 210 & 1.197 & .421 & 2.38 \\
\hline C & 3 & 300 & 1.710 & .313 & 3.19 \\
\hline D & 2 & 360 & 2.052 & .185 & 5.40 \\
\hline E & 1 & 390 & 2.223 & .116 & 8.62 \\
\hline $\mathrm{F}$ & 1 & 420 & 2.394 & .0628 & 15.9 \\
\hline G & 1 & 430 & 2.451 & .0537 & 18.6 \\
\hline $\mathrm{H}$ & $I$ & 440 & 2.508 & .0133 & 75.1 \\
\hline Critical & 0 & 446 & 2.542 & $(0)$ & $(\infty)$ \\
\hline
\end{tabular}

After loading $F ;$ the source was removed from the central thimble and placed in the regular source hole on the periphery of the fuel container, where it is remotely controllable. A new choice of "multiplication one" counting rates was made by setting all counting rates with the repositioned source equal to "multiplication 16 " at loading F.

At $3: 45$ P.M. on July 25, $1953^{\circ}$ the $\mathrm{SP}$ reactor went critical with $2.54 \mathrm{Kg}$ of $\mathrm{U}^{23}$

Figure 12 shows a plot of inverse multiplication vs. kilograms of U235 added. This plot is compared with curves assuming proportionality between $1 / M$ and the fractional fuel load: (1) for a critical mass of $2.74 \mathrm{~kg}$, which was obtained at KAPL; and (2) for a critical mass of $2.54 \mathrm{~kg}$, which was obtained here. Except for the first two loadings, the "theoretical" curve for $2.54 \mathrm{~kg}$ was followed fairly well. One interesting feature is the sudden increase in multiplication from loading $G$ to $H$. This occurred because loading $H$ closed the ring of fuel elements, providing a more symmetrical flux pattern and less leakage. Likewise, loading G made a more unsymmetrical flux pattern and caused less multiplication than was expected.

On the first critical run the reactor contained 446 discs, with 30 fuel discs on 14 rods and 13 discs on each of the two remaining rods. The effective $\mathrm{K}$ was estimated to be 1.0039. Later, the fuel was loaded in a more symmetrical 
pattern, and criticality wäs àchleved with 27 discs on 12 rods and 26 discs on 4 rods symmetrically placed in the fue container. This is a total of $428 \mathrm{discs}$, or $2.44 \mathrm{~kg}$, some 270 grams less than that required at KAPL for the TTR.

At this point enough extra fuel was added ( 4 more discs) to make $\mathrm{K}_{\text {eff }}=1.0040$. The final fuel configuration was 27 discs on 16 rods, or 432 discs $=2.46 \mathrm{~kg}$. The last four discs were added in such a manner that they gave the effect of uniformly increasing the fuel concentration, i.e., all the fuel discs on the rods were respaced to be equidistant after the addition of the last disc. They were added one at a time, in order to determine the total $\mathrm{K}_{\text {eff }}$ and the worth of individual fuel discs. Table II gives the data.

TABLE II. Keff VS. NUMBER OF FUEL DISCS

$\begin{array}{ccc}\text { NO. OF DISCS } & \begin{array}{c}\text { FREE PERIOD (SEC.) } \\ \text { IN TANK }\end{array} & \frac{K_{\text {eff }}}{1 \text { (ALI RODS OUT) }} \\ 428 & 70 & 1.00095 \\ 429 & 28 & 1.00173 \\ 430 & 14 & 1.00250 \\ 431 & 106(1) & 1.00320 \\ 432 & 83(2) & 1.00403\end{array}$

Note 1: Period measured from critical rod positions with 430 discs.

Note 2: Period measured from critical rod positions with 431 discs.

Therefore, the final Keff of the reactor 1 s 1.0040 , and the last four fuel discs are worth an average $0.076 \% \Delta \mathrm{K}$ each.

CALIBRATION

Coarse Controli Rods . The right control rod was calibrated in one-1nch increments by periods. For example: the pile was found to be critical with the left control rod set at 16 inches ( 1 .e., it had been pulled 16 inches out of the reactor), the right rod at 3 inches and the fine rod at 1.00 inch. The right rod was thennmoved to 4 inches and the period measured. This was repeated in one-inch steps until the right rod was at 9 inches. (W1th the right rod removed farther than this the perlods were too small to be measured accurately). The pile was then made critical with the left

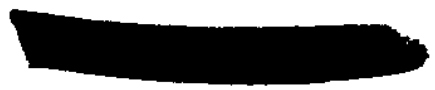


rod at 9 inches, the right rod at 9 inches, and the fine rod at 2.500 inches. Then the right rod was moved to 10 inches, a period measured, and this was repeated until the right rod was at 16 inches, the limit of 1 ts traverse. The $0-3$ inch portion of the rod was callbrated by measuring negative pertods.

Table III gives the results of the right coarse control rod calibration. It should be remembered that these calibration measurements are difference experiments and therefore the one-inch calibrations have rather large errors (5-10\%). However, the total worth of the coarse rod is known more accurately; it is $0.39 \neq .01 \% \mathrm{~K}$. Figure 13 is a smooth plot of the control rod calibration.

Fine Control Rods The fine control rod is a stainless steel rod that can be set by a position-demand servo system to 0.001 inch. The calibration method was similar to that of the coarse rod. Again, the data for the incremental changes are not very accurate, but the total worth of the rod, 19 in, is quite accurate. 
TABLE III. RIGHT COARSE CONTROL ROD CALIBRATION

\begin{tabular}{|c|c|c|}
\hline $\begin{array}{c}\text { POSITION CHANGE } \\
\text { (INCHES) }\end{array}$ & $\Delta \mathrm{K}(\%)$ & $\Delta i h^{*}$ \\
\hline $0-1$ & .0052 & 2.0 \\
\hline $1-2$ & .0091 & 3.5 \\
\hline $2-3$ & .0137 & 5.3 \\
\hline $3-4$ & .0240 & 9.2 \\
\hline $4-5$ & .0254 & 9.8 \\
\hline $5-6$ & .0316 & 12.2 \\
\hline $6-7$ & .0350 & 13.5 \\
\hline $7-8$ & .0310 & 11.9 \\
\hline $8-9$ & .0340 & 13.1 \\
\hline $9-10$ & .0325 & 12.5 \\
\hline $10-11$ & .0315 & 12.1 \\
\hline $11-12$ & .030 & 11.5 \\
\hline $12-13$ & .023 & 8.8 \\
\hline $13-14$ & .022 & 8.5 \\
\hline $14-15$ & .011 & 4.2 \\
\hline $15-16$ & .016 & 6.2 \\
\hline Total worth: & $.3750 \%$ & 144.0 \\
\hline
\end{tabular}

* The conversion to inhours is obtained from: . $\Delta K(\%)=2.6 \times 10^{-3} \times \Delta$ in 
Table IV gives the fine control rod calibration.

TABLE IV. FINE CONTROL ROD CALIBRATION

\begin{tabular}{ccc}
$\begin{array}{c}\text { POSITION CHANGE } \\
\text { (INCHES) }\end{array}$ & \multicolumn{1}{c}{$\Delta \mathrm{K}(\%)$} & \multicolumn{1}{c}{$\Delta$ in } \\
\cline { 2 - 3 } $0-1$ & .003 & 1.2 \\
$0-4$ & .010 & 3.8 \\
$4-8$ & .014 & 5.4 \\
$8-12$ & .016 & 6.1 \\
$12-16$ & .009 & 3.5 \\
$0-16$ (Total worth) & .049 & 18.8
\end{tabular}

Safety Rods ... The four fast-acting cadmium safety rods were calibrated by two different methods with reasonable agreement.

Rod Drop Method If a rapid reactivity change is made in a reactor and the instantaneous pile power change from $F o$ to $F$ is measured, then:

$$
\Delta \mathrm{K}=\left(\frac{\mathrm{F}-\mathrm{FO}}{\mathrm{F}}\right) \not \mathrm{s} \text {, where }
$$

$\$$, the "dollar", represents a reactivity change of 0.0073 . The signal from a neutron sensitive ion chamber was amplified by a vibrating reed electrometer and then fed to a linear amplifier. The instantaneous change in the output of the amplifier was measured on a Brush Recorder when the safety rods were dropped. Table V gives the data obtained.

TABLE V. CALIBRATION OF SAFETY RODS BY ROD DROP METHOD

RODS DROPPED

1

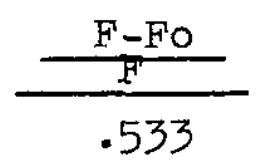

1.19

$\frac{\Delta \mathrm{K}(\%)}{0.39}$

1 and 2

2.11

0.87

$1,2,3$, and $4^{\prime}$ (scram) 1.54 (1) 
Subcritical Multiplication Method. A LiI (TI) scintillation counter was used in this method. Although any type counter could have been used, this one was chosen because of its high sensitivity. It gives a counting rate thirty times that of a boron-lined proportional counter in the same flux. Thus the scintiliator could be located far enough from the pile to "see" the pile as a whole and not be affected by local changes in geometry due to movement of control rods, etc. The reactor was made critical and a known amount of negative reactivity, $\Delta K_{1}$ was added with the coarse control rod and the source was inserted. After the pile flux was level, a count $c_{1}$, was taken. The critical rod settings were reproduced, a safety rod was dropped, and a count, $c_{2}$, was taken when the flux had leveled off. $\Delta K_{2}$ due to the safety rod dropped is then given by:

$$
\frac{c_{1}}{c_{2}}=\frac{1-K_{2}}{1-K_{1}}=\frac{\Delta K_{2} ;}{\Delta K_{1}} \quad \Delta K_{2}=\frac{c_{1}}{c_{2}}\left(\Delta K_{1}\right)
$$

Table VI gives the results of the safety rod calibrations.

\section{TABLE VI. SAFETY ROD CAIIBRATION}

ROD NUMBER

1

$$
\begin{array}{r}
1 \text { and } 2 \\
1,2 \text { and } 3 \\
1,2,3 \text { and } 4
\end{array}
$$

These results indicate that the safety rods singly are worth $0.4 \%$ negative $\Delta \mathrm{K}$ and that all four rods are worth $-1.5 \% \Delta \mathrm{K}$.

Shut-down Sheet. ' The worth of the Number 6 shutdown sheet was measured to be $0.89 \%$ by the subcritical multiplication method.

Other Measurements Removing the top west experimental graphite port resulted in a $0.11 \%$ negative $\Delta K$ reactivity change. Removing all three experimental ports resulted in $-0.49 \Delta \mathrm{K}$. Dralning all the 011 resulted in approximately $-20 \% \Delta K$.
NEGATIVE REACTIVITY, $\triangle \mathrm{K}(\%)$

$$
0.38
$$

0.80

1.21

1.53 
Absolute Flux Calibration

In order to estimate the power of the pile, the absolute thermal neutron flux in the exact center of the reactor was measured with standard gold foils. These foils were part of a set which had been calibrated in the Argonne National Laboratory standard pile.

KAPL-832 gives $\mathrm{nvth}_{\mathrm{th}}=3.4 \times 10^{7} \mathrm{n} / \mathrm{cm}^{2} \mathrm{sec}$. watt, measured in the center of the TTR. Assuming an identical flux distribution in the SP (an assumption certainly within the error of the absolute flux determination), it was possible to estimate the power of the SP in terms of the current produced in one of the ion chambers placed nearby.

At the present time this figure no longer holds since the fuel has been rearranged, the chamber moved and the pile geometry changed. The measurement will be repeated when the exponential tank is in place.

Flux Survey of the Exponential Pedestal ' The exponential pedestal is a cylinder 5 feet in diameter and $163 / 4$ inches high, resting on top of the 5-foot cube of reactor graphite. As described on page 9 , there is on the east face of the 5-foot graphite cube, a centered 4-foot graphite cube, called the thermal column extending into the shielding wall. The central thimble extends through the thermal column. The reactor itself is placed in the reactor room so that the east face of the 5-foot cube is 6 inches from this 6-foot thick concrete wall, the west face is about 20 feet from a similar wall, and the two remaining faces are 6 feet from the north and south walls.

Flux measurements with bare and cadmium-covered indium foils were made on top of the exponential pedestal to determine if the flux distribution was suitable for exponential experiments. Unfortunately, the first flux surveys showed serious asymmetry, and corrective measures had to be applied.

The uppermost curve of Figure 14 shows the relative flux as measured with indium-foils along the east-west diameter of the pedestal. This illustrates that (I) the flux was approximately twice as high on the east edge as on the west edge, (2) the highest point in the flux is somewhat to the east of center, and (3) there is a flux depression near the center. The north-south distribution (not presented) is symmetrical, has a flux depression in the center, and the flux is higher at the edges than at the west boundary, by about $12 \%$.

The dotted curve of Figure 14 represents an idealized flux distribution for an infinite graphite cylinder in a 
vacuum. It is a zero order Bessel function with an extrapolation distance of $0.71 \lambda_{t}=0.75$ inches. That a similar distribution was not observed is due, in part, to higher harmonics arising from the mismatch at the cube-cylinder interface and, In part, to reflections from the walls. A cadmium cover for the outside of the pedestal which would tend to reduce these effects had not arrived at the time of this experiment.

The presence of high harmonics was further demonstrated in northeast-southwest and northwest-southeast traverses. In these no central flux depression was observed. The net effect is a "scalloped" flux distribution out to about six inches from the center.

Figure 15, a flux contour map of the pedestal, demonstrates more clearly the presence of the harmonics and the perturbations they cause near the center. Figure 16 shows the variations in the indium-cadmium ratio.

From these curves it is evident that the presence of the thermal column moves the flux center of the reactor, and also provides a rather large thermal neutron leak into the pedestal, as confirmed by the large cadmium ratios on the east side of the pedestal. Figure 17 shows the relative flux distribution along the central thimble of the reactor itself. The asymmetry is even larger there. The main cause of the asymmetry is therefore the thermal column, and not the proximity of the shielding wall. If the effect of the shielding wall had predominated, one would have expected lower cadmium ratios on the east side due to reflection of fast neutrons from the wall.

The thermal column was removed and a 0.030 -inch cadmium sheet was wrapped around the pedestal. Diametric flux plots on the pedestal top showed good agreement with a $J_{0}$ distribution.

To utilize either the thermal column or the exponential experiment without major rearrangements, short lengths of I-inch cadmium rods were inserted into the graphite, 4-3/16 inches on center, at the interface between the reactor and the thermal column. These rods are easily removable when the thermal column is needed. The lateral area of the pedestal and the exposed top of the 5-foot graphite reflector were lined with a 0.030 -inch cadmium sheet.

Under these conditions the relative flux on the pedestal top was again measured with indium and cadmium-covered indlum folls. The east-west diameter relative flux curve is the middle one in Figure 14. The experimental points fall 
quite we11 on a $J_{0}$ curve using an extrapolation distance of 2.5 inches. Comparison with the upper curve demonstrates the improvement. The normalization of the curves of Figure 14 to a common value at the center of the pedestal is somewhat arbitrary. The small amount of harmonic content st111 present is not considered harmful; it should damp out rapidiy in the lowest few feet of the exponential tank.

Figure 18 shows the indium-cadmium ratio and eplcadmium activity on the pedestal top after the above changes had been made. Comparison with Figure 16 demonstrates that the slow flux hump on the east side has disappeared.

\section{MISCELLANEOUS MEASURENENTS}

Reactivity of a Natural Uranium Slug

The addition of an SRP sIug (natural uranium) to the central thimble is worth an additional 62 inhours of reactivity. A similar slug is worth 1.5 inhours in a 305-type pile.

An " $A$ " slug and a "B" slug were compared in the central thimble. These slugs differ in that the diameter specification for a " $B$ " slug is about $0.4 \%$ less than that for an " $A$ " slug.

Danger coefficient data indicated that the smaller of the two causes a reactivity change $0.5 \%$ less than the larger.

Measurements of Radiation Levels While Operating RadiaElon levels around the outside of the reactor room, the exponential room in the nuclear physics laboratory (into which the thermal column extends), and outside the building were checked by $W$. J. Heaney and P. F. Donovan of the Radiation Control Group. The results are given in Appendix A.

The general conclusions were that if the pile is operated at a power of 25 watts or greater, additional shielding will be required near the doors to the reactor noom and exponential room. At lower power levels (but greater than 1 watt), access to the area outside the SP door on the ..15foot level should be controlled.

It is estimated that these exponential measurements will require about 5 watts, and that operation at higher powers wil1 be very infrequent.

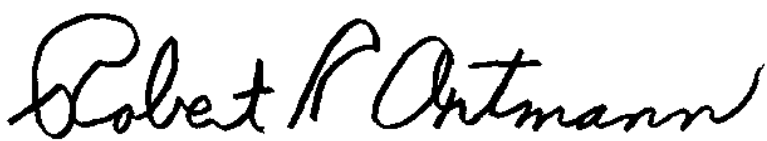

Robert C.Axtmann

Experimental Pile Physics Division 


\section{ACKNOWLEDGEMENTS}

A great many members of du Pont and General Electric have contributed to the design of the Standard Pile. Some of these deserve special credit. $H . B$. Stewart and $F . G$. LaViolette of the Knolis Atomic Power Laboratory made sub- stantial contributions to the conceptual design. Dr. Stewart had been largely responsible for the design of the original TTR. J. I. Matrone was in charge of the group in the General Engineering Laboratory of the General Electric Company responsible for mechanical design and construction. G. Dessauer, assisted by K. H. Doeringsfeld and T. R. VickRoy, developed the design specifications for du Pont.

The original Standard Pile crew consisted of the authors of this report. L. J. Vachon joined the group for later experiments. G. Dessauer participated in the startup and in the planning of the subsequent experimental program. R. N. poole and R. A. Dewes of the General Electric Company contributed much to the success of the erection of the reactor and the initial approach to criticality. Dean Brown gave assistance in the interpretation of theoretical matters. $K$. $H$. Doeringsfeld and G. F. O'Ne1li tested and calibrated the instruments before they were placed in service on the pile. G. B. Carlton suggested the isolation of the thermal column by cadmium rods. 


\section{APPENDIX}

MEMORANDUM

TO: R. C. AXTMANN, Experimental P1le Physics

FROM: W. J. HEANEY, Radiation Control Group

On August 18, 1953, the standard Pile was brought to a power level of 10 watts. At this time, the Radiation control Group exposed film and pencils at known or suspected leaks in the shielding system. Meanwhile an extensive survey was made around the shield to detect any other defects. A Thyac and a scintillation neutron detector were used to locate radiation. Cutie Ples, Hurst Dosimeters, Slow Neutron Pencils, and film were used to determine the magnitude of the dose rate. The highest level of radiation was found to be at the door to the reactor room at the 15-fott level. Here the level was $80 \mathrm{mrem} / \mathrm{hr}$. This total is composed of $12 \mathrm{mrem} / \mathrm{hr}$. from the fast neutrons, $41 \mathrm{mrem} / \mathrm{hr}$. due to slow neutrons and $27 \mathrm{mr} / \mathrm{hr}$ from the gamma field. The MPL (maximum permissible limit) is $300 \mathrm{mrem} / \mathrm{wk}$, corresponding to a steady dose of $6.25 \mathrm{mrem} / \mathrm{hr}$., in a 40 hour week.

The crack made by the junction of the south shield wall with the portion removable for a and thermal column was a suspected source of leaks. Checks with the detection instruments and with pencils and film showed no leaks.

Measurements were made in the Nuclear Physics Laboratory at the thermal column and at the flanges above it. While there was about $2,000 \mathrm{c} / \mathrm{m}$ detected with the Thyac, and the neutron scintillator responded weakly, no dose rate was observed.

Radiation level at the door to the exponential room was $13 \mathrm{mr} / \mathrm{hr}$ : due to gammas. Fast neutrons were detected, but the dose rate was insignificant. The slow neutron component was calculated to be about $18 \mathrm{mrem} / \mathrm{hr}$.

Low level radiation was detected, but no measurable dose rate was found either in the control room or on the roof.

On September l7th the power was raised to 25 watts and other measurements were made. The gamma flux at the reactor door had increased to $60 \mathrm{mr} / \mathrm{hr}$. and the slow neutron level to $110 \mathrm{mrem} / \mathrm{hr}$. This corresponds to the expected increase of $21 / 2$ times. The fast neutron dose rate was read to be $14 \mathrm{mrem} / \mathrm{hr}$. This is not in the same ratio, but with a low

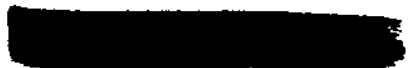


scale reading, errors in zero setting, calibration, reading, and technique are proportionately more significant and account for the discrepancy.

At 25 watts the SN-flux at the exponential door was 46 mrem/hr., F.N. flux was $4 \mathrm{mrem} / \mathrm{hr}$. and the gamma radiation was $30 \mathrm{mr} / \mathrm{hr}$ which is consistent with the lower level readings:

By this time, the thermal column had been modified, and there was a radiation field of $65 \mathrm{mrem} / \mathrm{hr}$. slow neutrons, 30 $\mathrm{mr} / \mathrm{hr}$. gamma rays, and $6 \mathrm{mrem} / \mathrm{hr}$. fast neutrons.

A summary of these findings is included in the following:

$8 / 18 / 53$

Reactor Door

Exponential Door
FN

SN

$\gamma$

$\gamma$

FN

$\mathrm{SN}$

$\gamma$
10 watts

$12 \mathrm{mrem} / \mathrm{hr}$.

$41 \mathrm{mrem} / \mathrm{hr}$.

$27 \mathrm{mr} / \mathrm{hr}$.

$80 \mathrm{mrem} / \mathrm{hr}$.

under $2 \mathrm{mrem} / \mathrm{hr}$.

$18 \mathrm{mrem} / \mathrm{hr}$.

$13 \mathrm{mr} / \mathrm{hr}$.

$31 \mathrm{mrem} / \mathrm{hr}$.
Total

Total

Thermal Columns (with shielding)

under $6 \mathrm{mrem} / \mathrm{hr}$.

Total

Control Room ....... under $6 \mathrm{mrem} / \mathrm{hr}$.

Total

Roof ......... under $6 \mathrm{mrem} / \mathrm{hr}$.

Total

$$
9 / 17 / 53
$$

Reactor Door

$$
25 \text { watts }
$$

FN

$14 \mathrm{mrem} / \mathrm{hr}$.

SN
$110 \mathrm{mrem} / \mathrm{hr}$.

$60 \mathrm{mr} / \mathrm{hr}$.

$184 \mathrm{mrem} / \mathrm{hr}$
Total 


$$
\text { 9/17/53 }
$$

Exponential Door

Thermal Column

(Modified by Insertion of Cadmium rods)
FN

SN

$\gamma$

FN

SN

$\gamma$
25 watts

$4 \mathrm{mrem} / \mathrm{hr}$.

$46 \mathrm{mrem} / \mathrm{hr}$.

$30 \mathrm{mr} / \mathrm{hr}$.

$80 \mathrm{mrem} / \mathrm{hr}$.

Total

$6 \mathrm{mrem} / \mathrm{hr}$.

$65 \mathrm{mrem} / \mathrm{hr}$.

$30 \mathrm{mr} / \mathrm{hr}$.

$101 \mathrm{mrem} / \mathrm{hr}$.

Total 


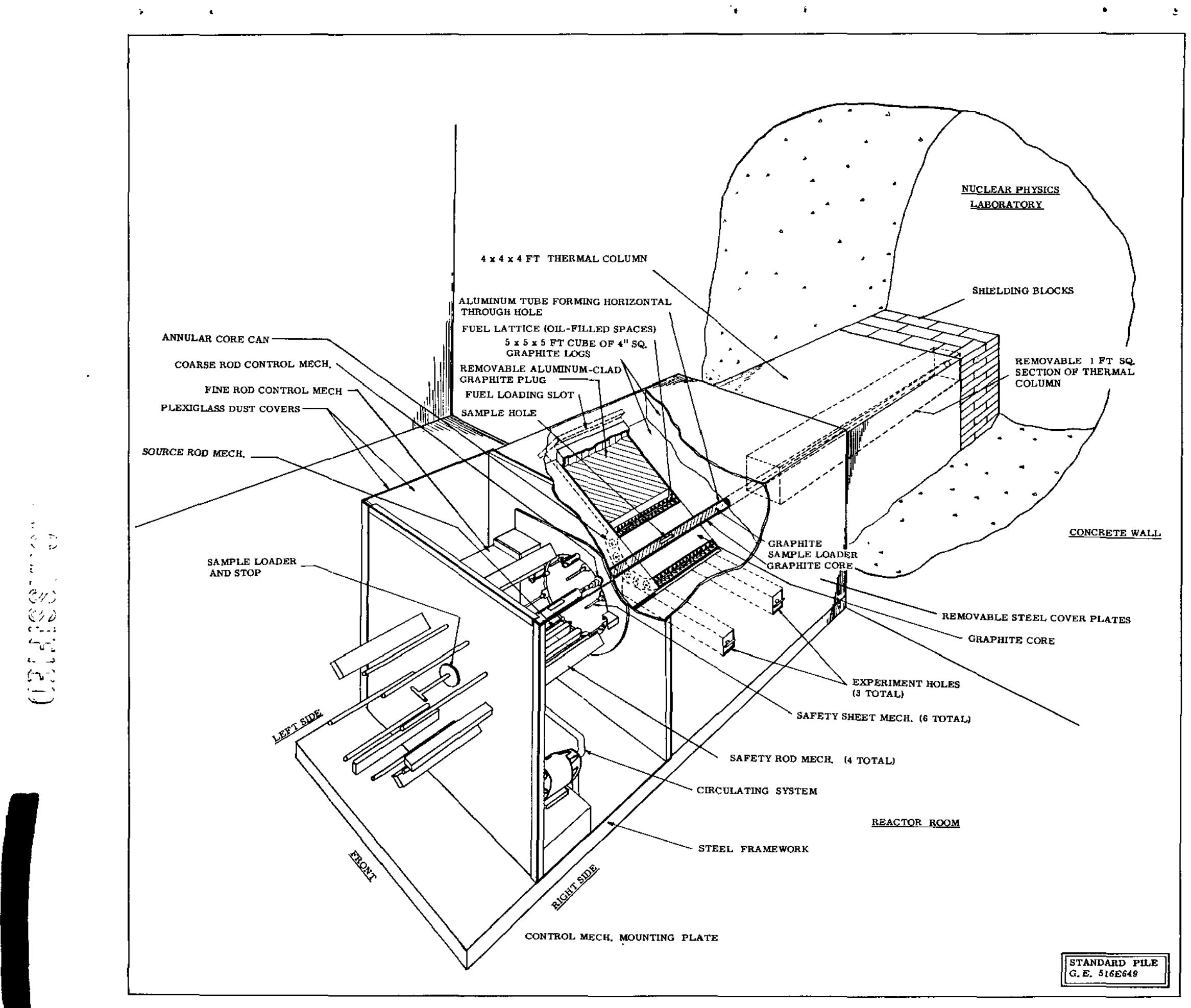



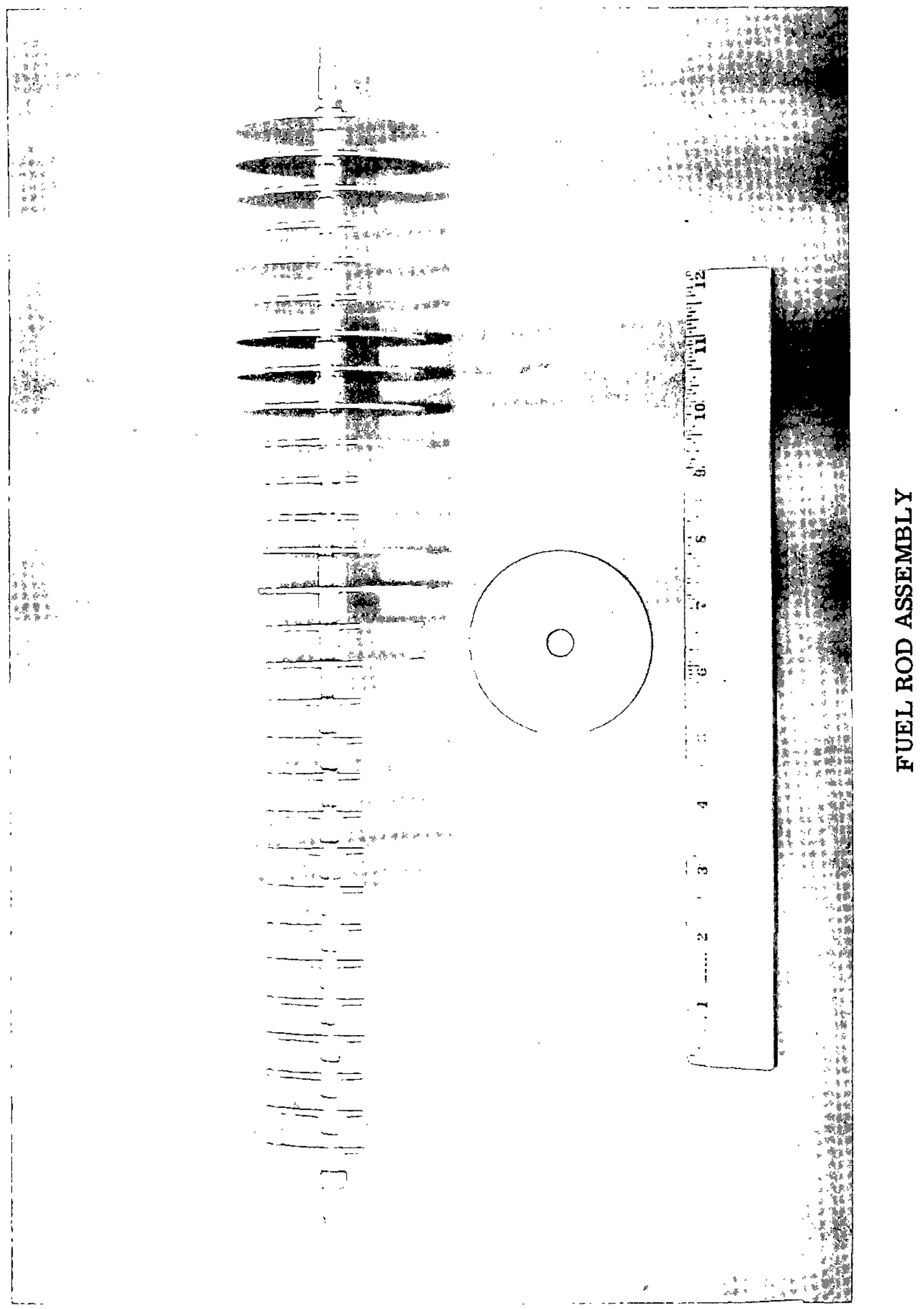

是
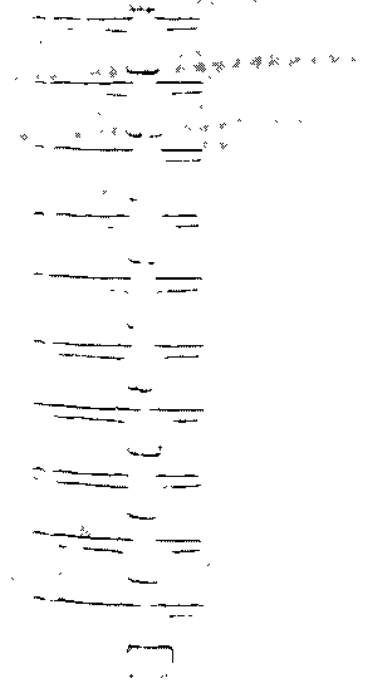


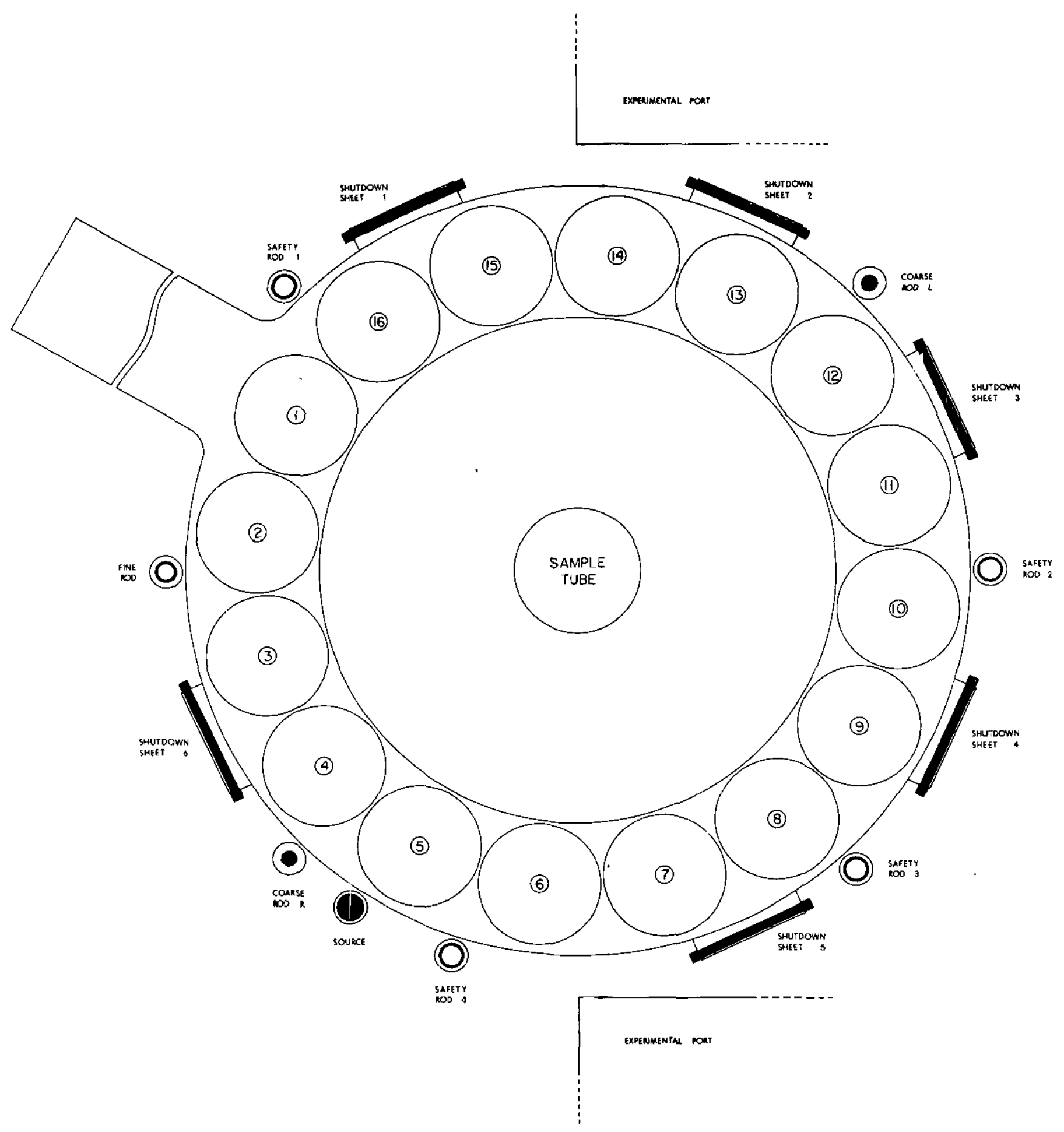

CROSS-SECTION OF THE REACTOR CORE 


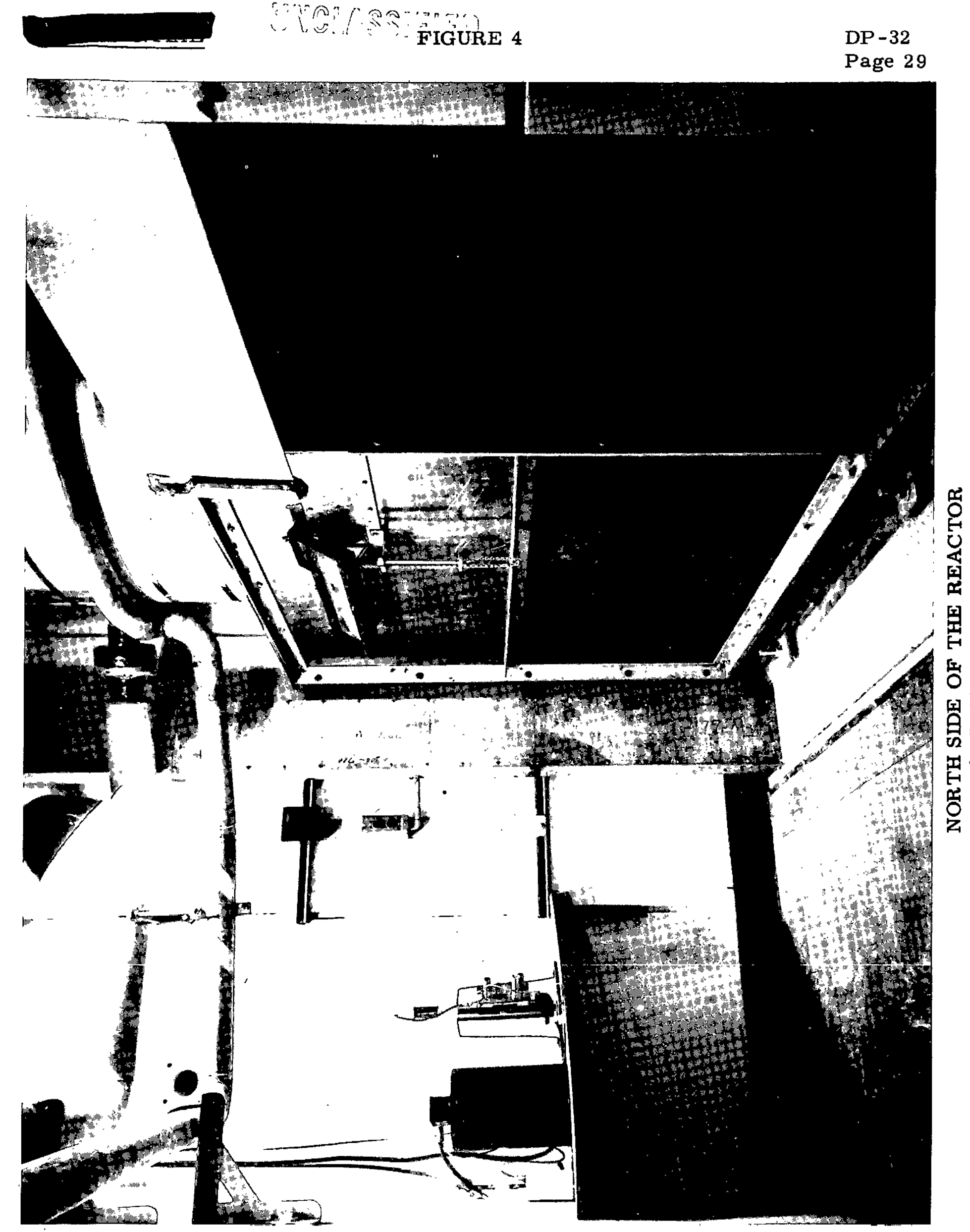

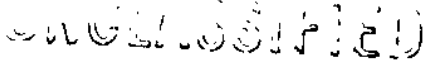




\section{FIGURE 5}

DP - 32

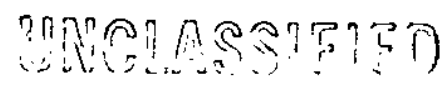

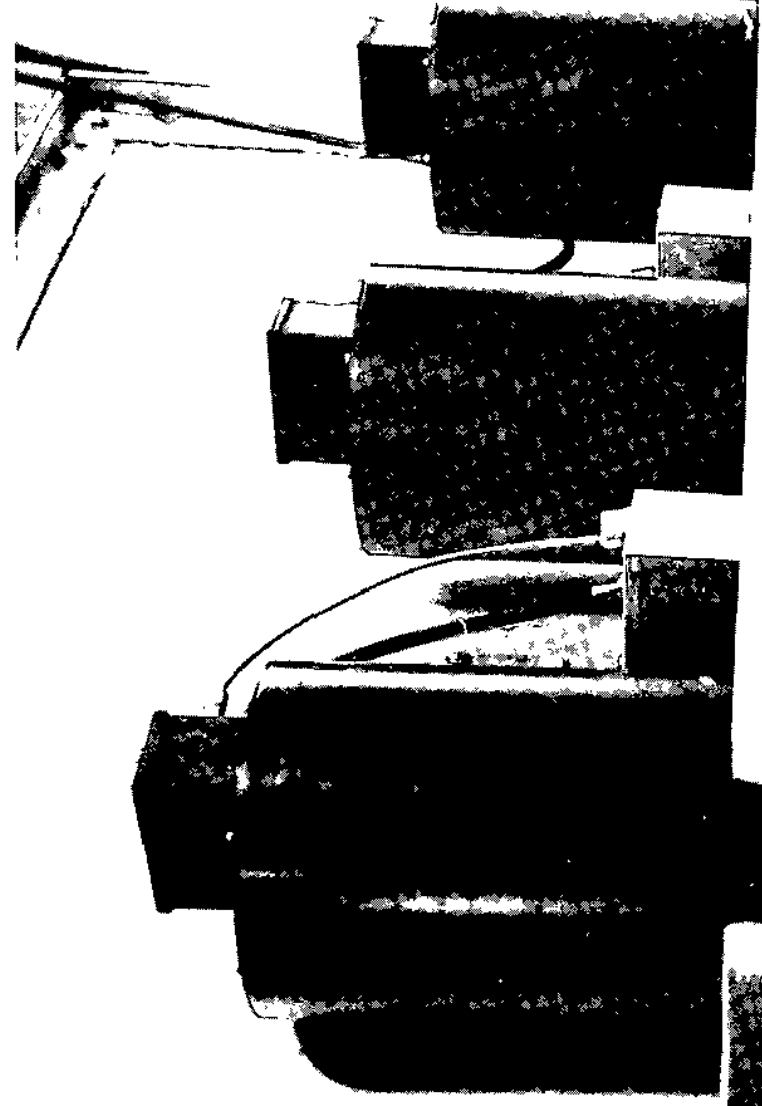

Suth
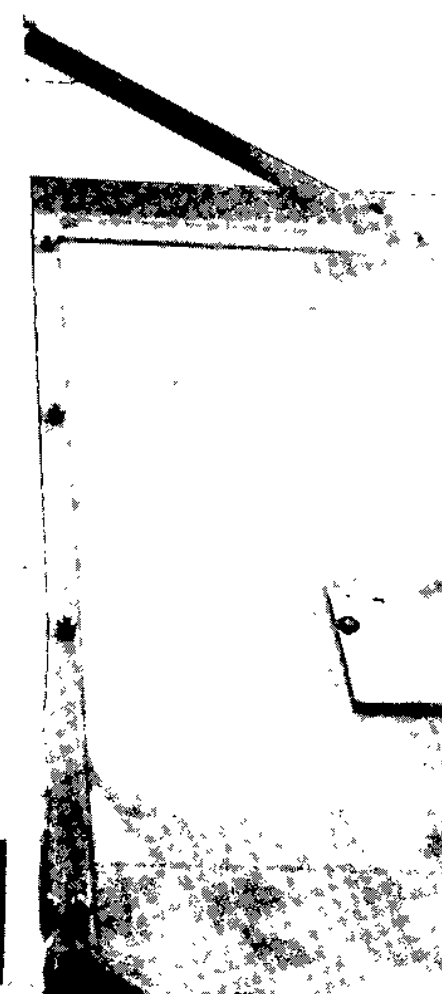

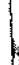

i
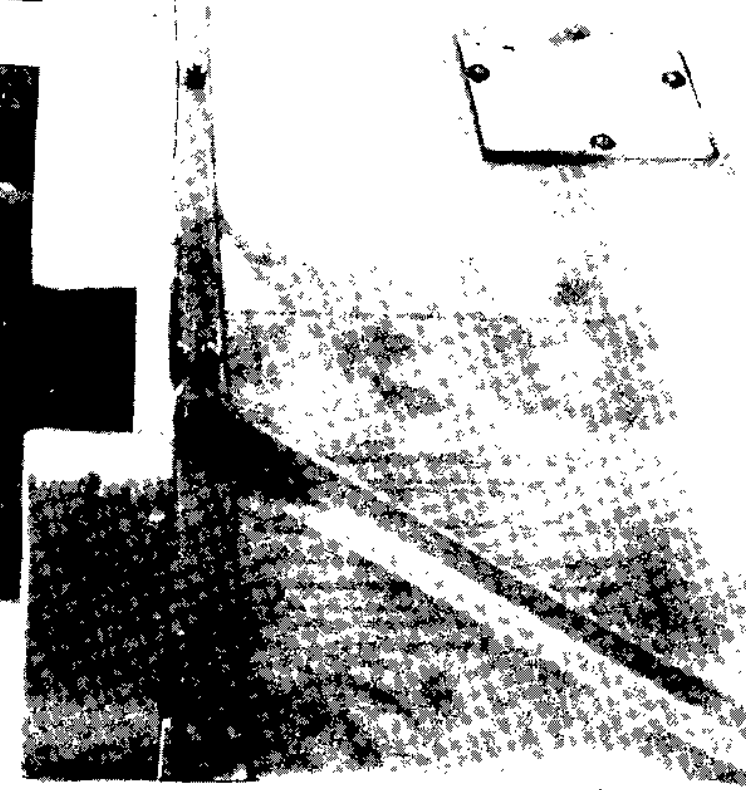

ond

Hon

( 30

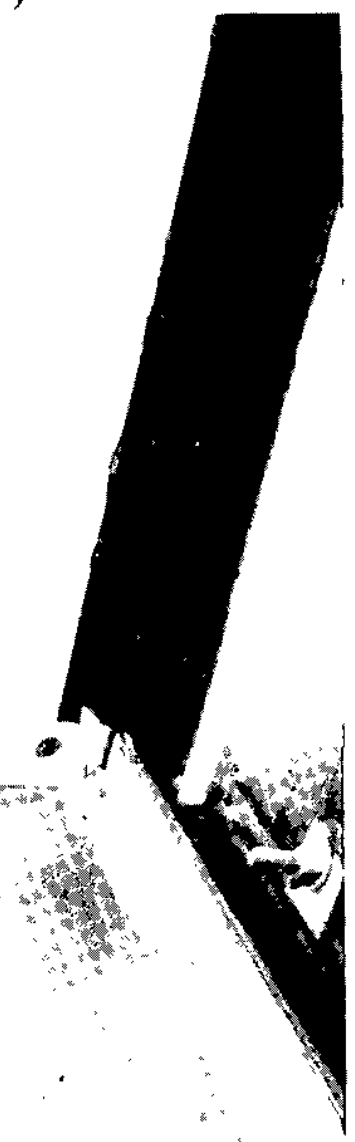

号

兵

鲳

))

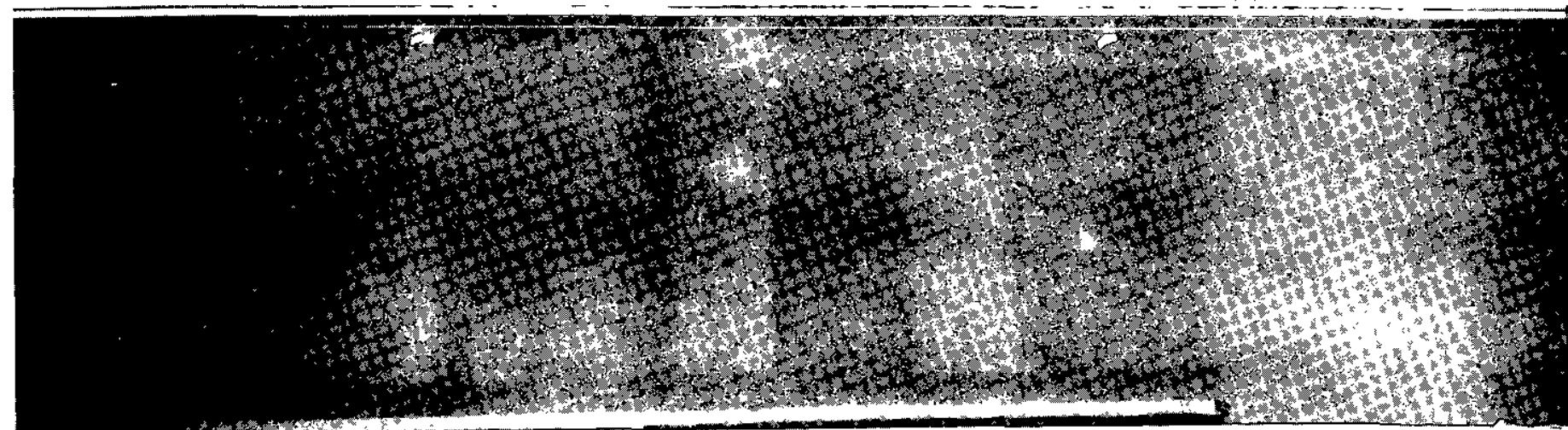

, n 


\section{Nand 6}

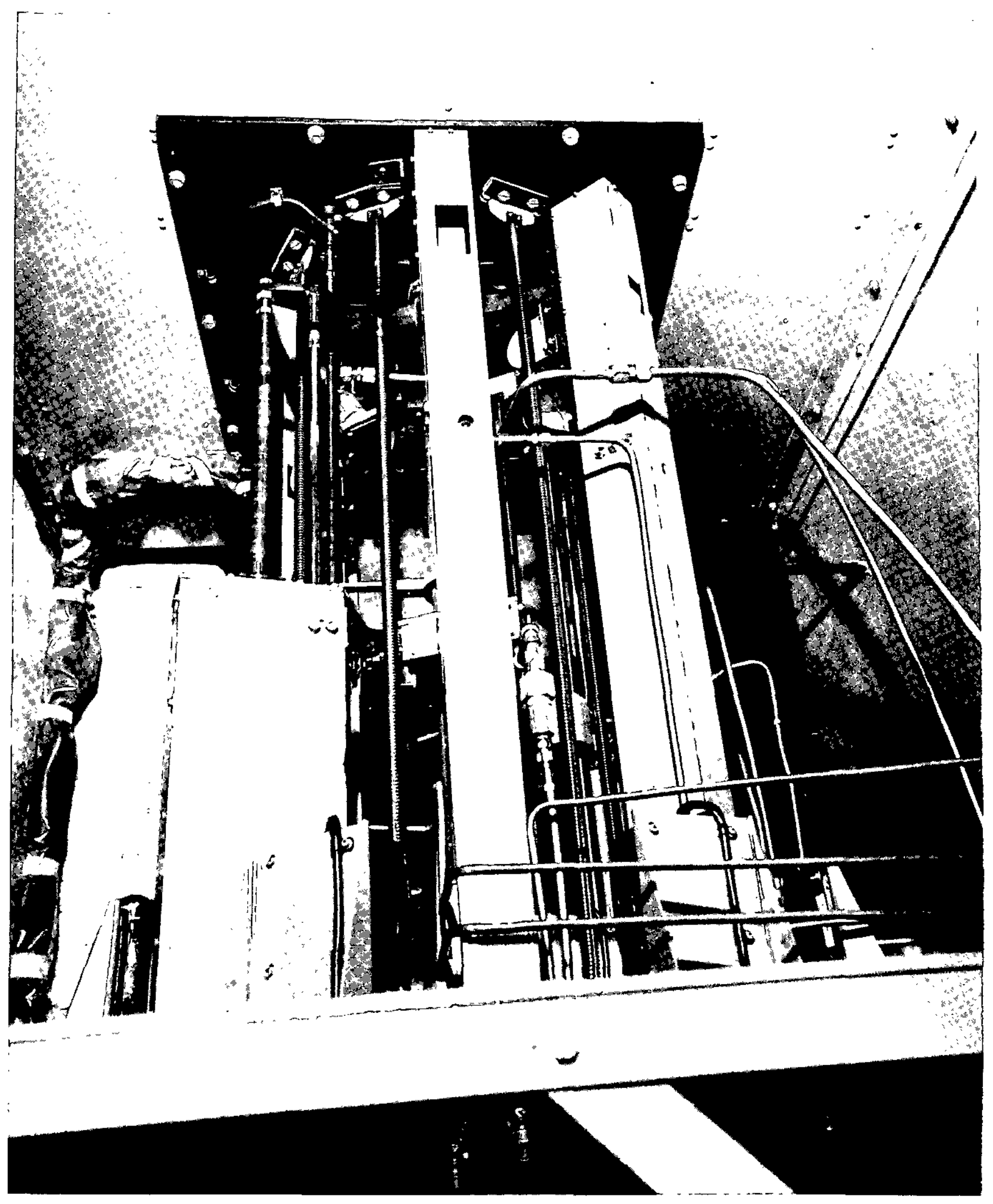

疍 


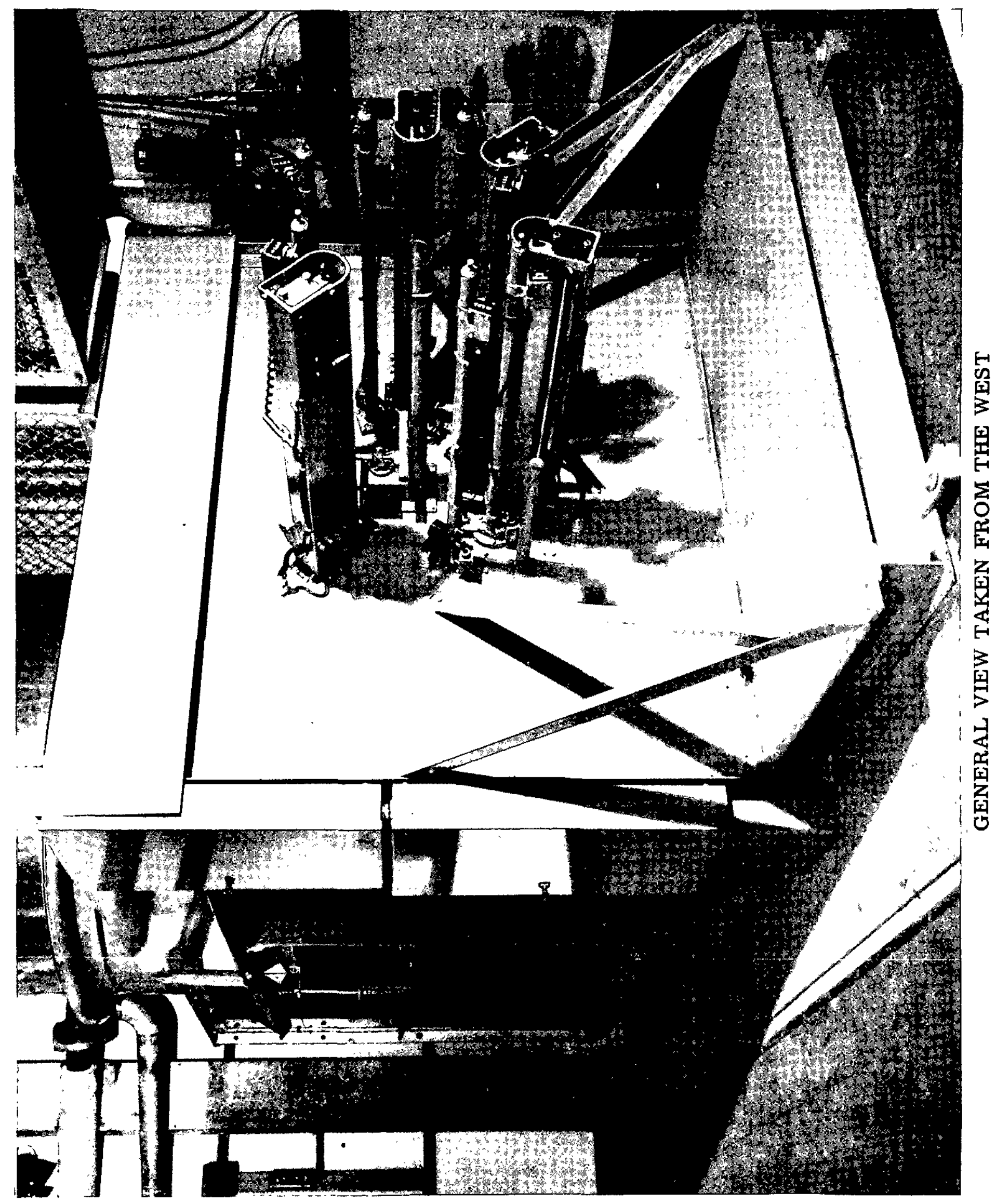



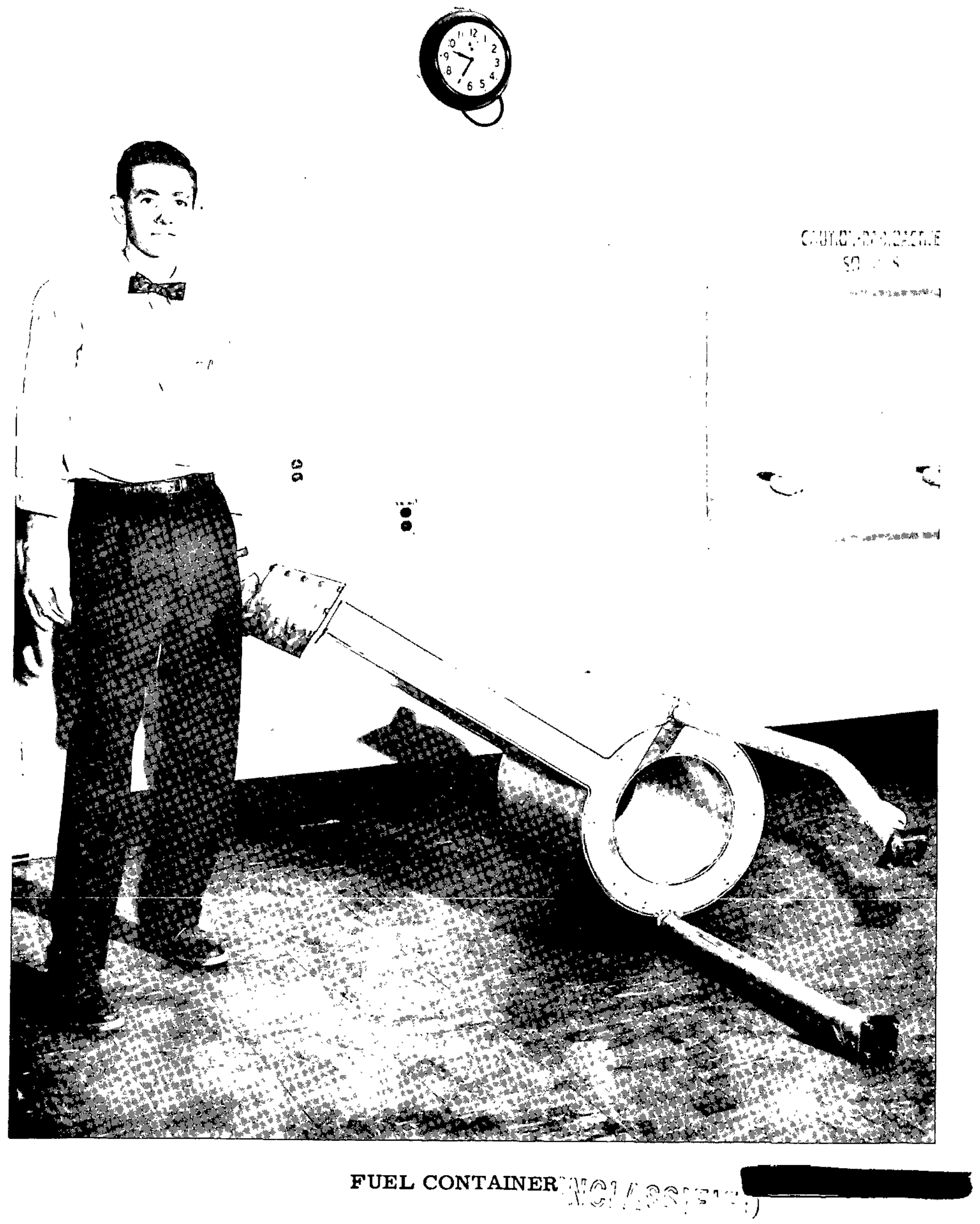


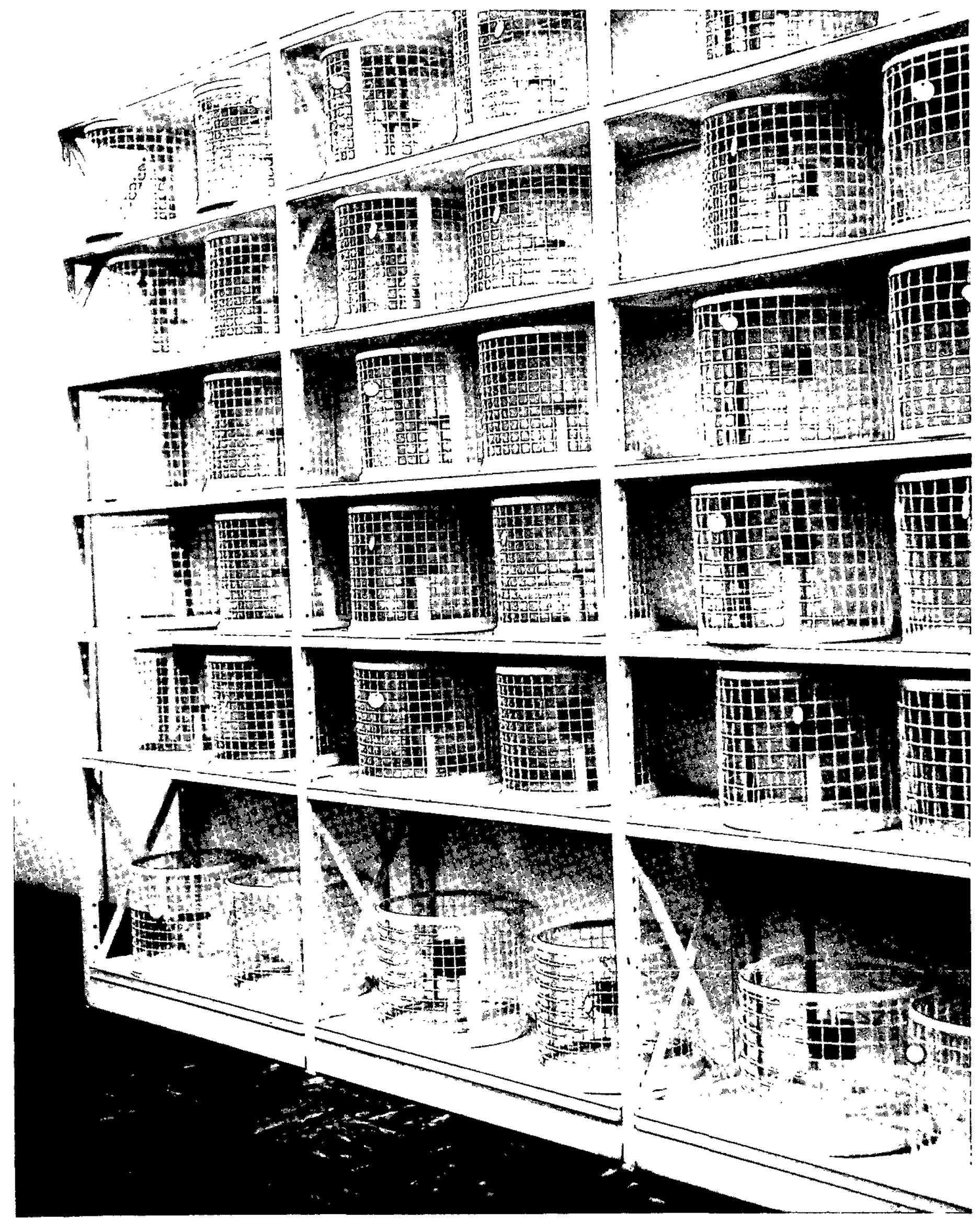




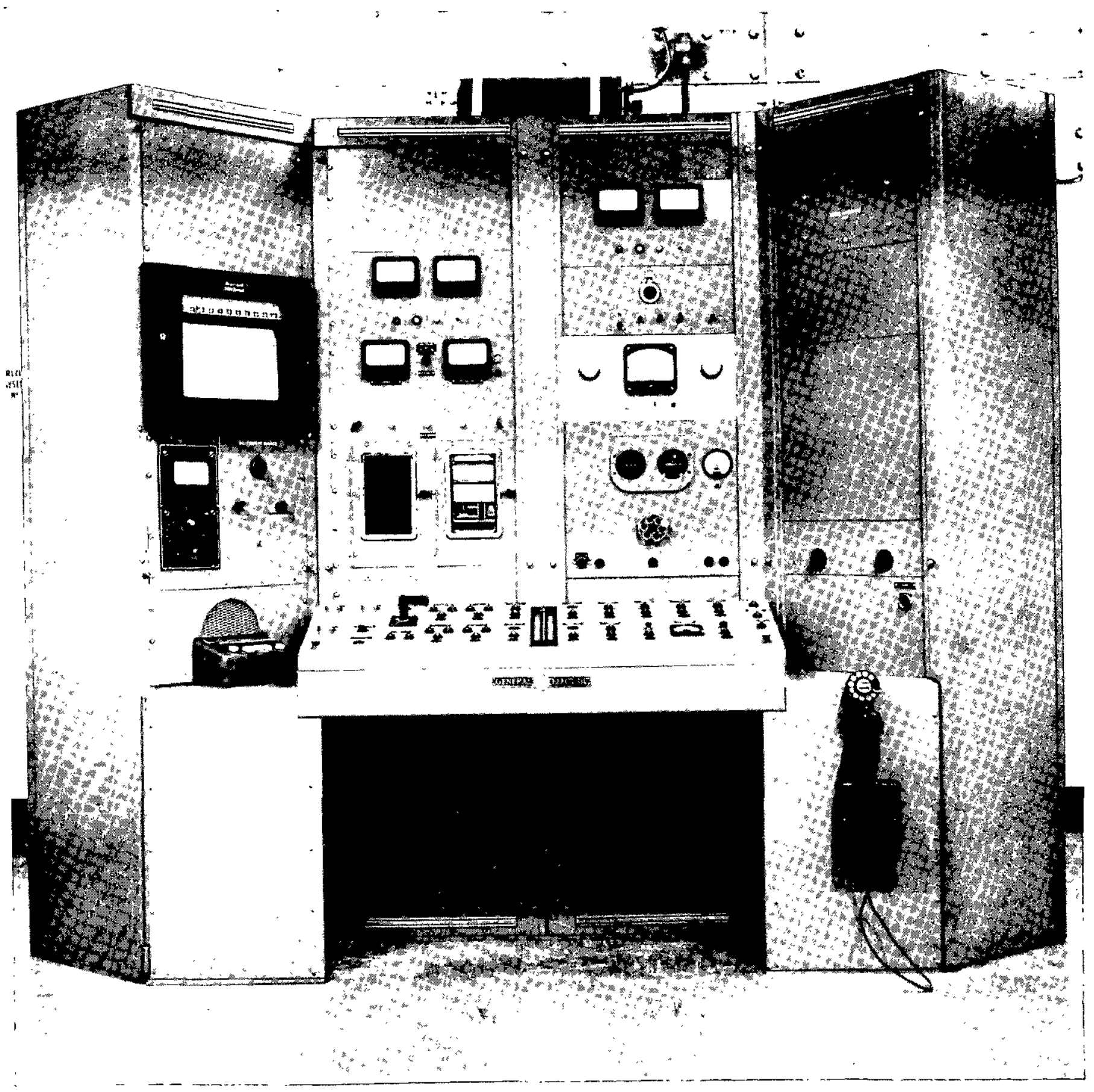

CONTROL CONSOLE 

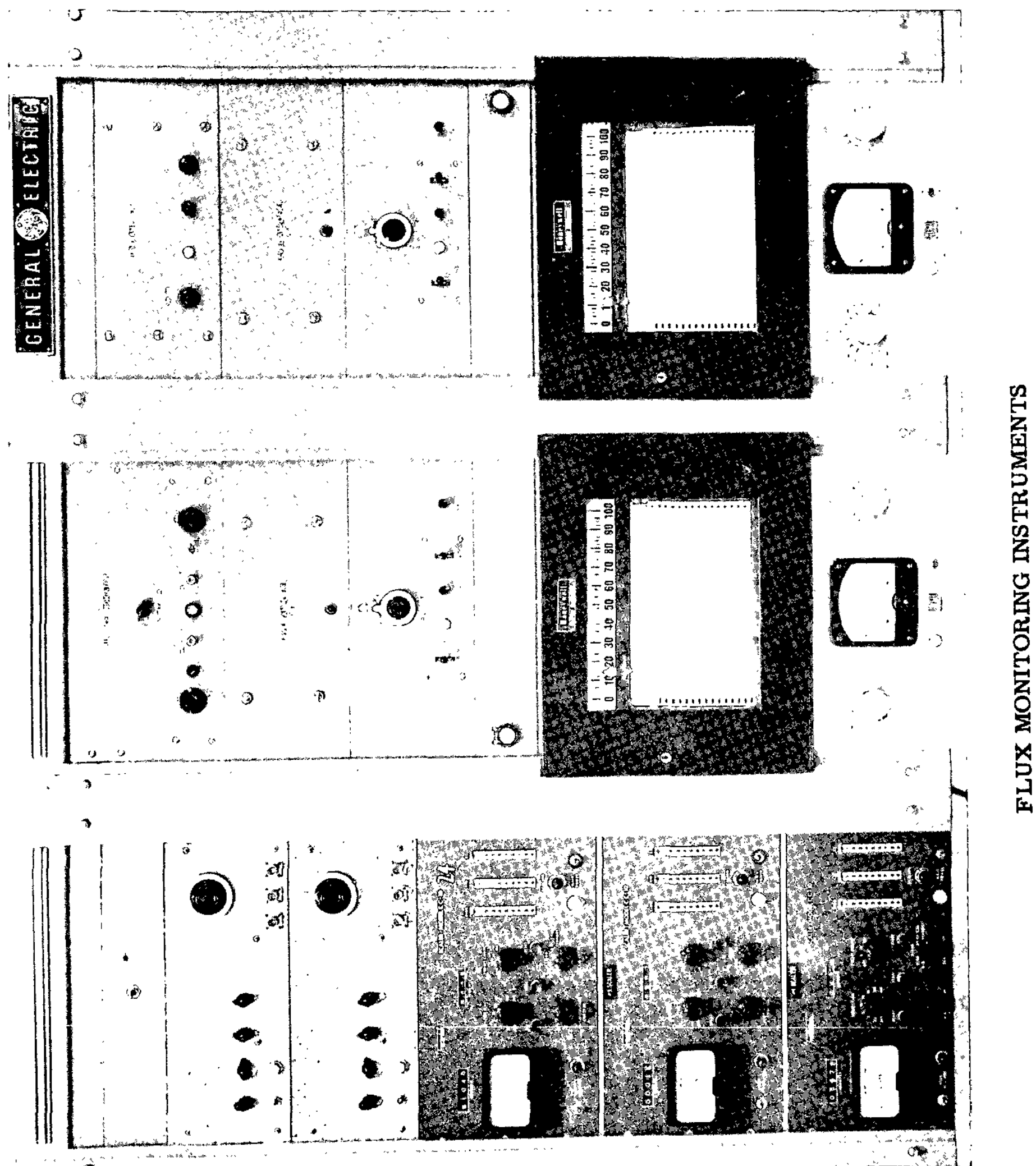


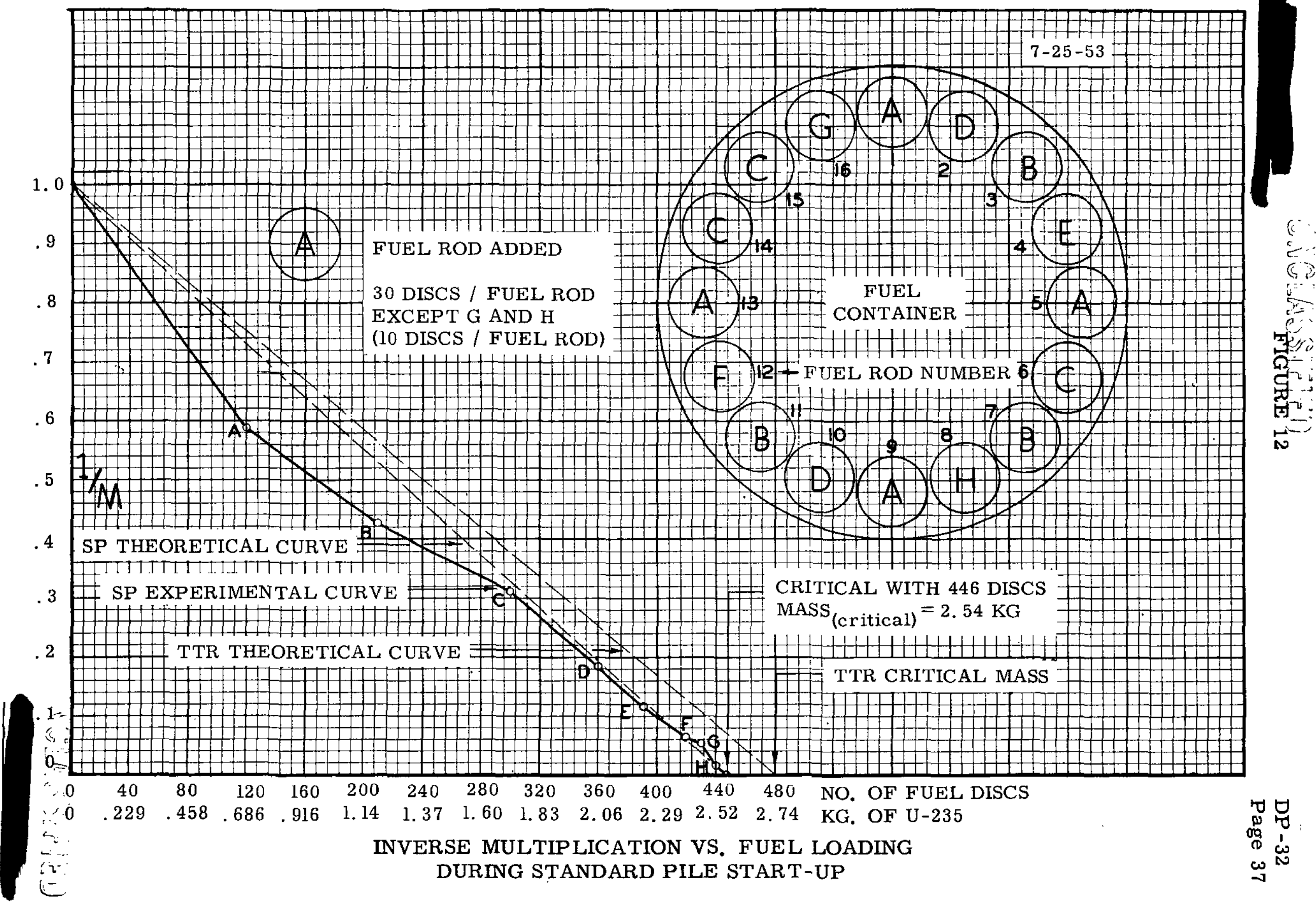




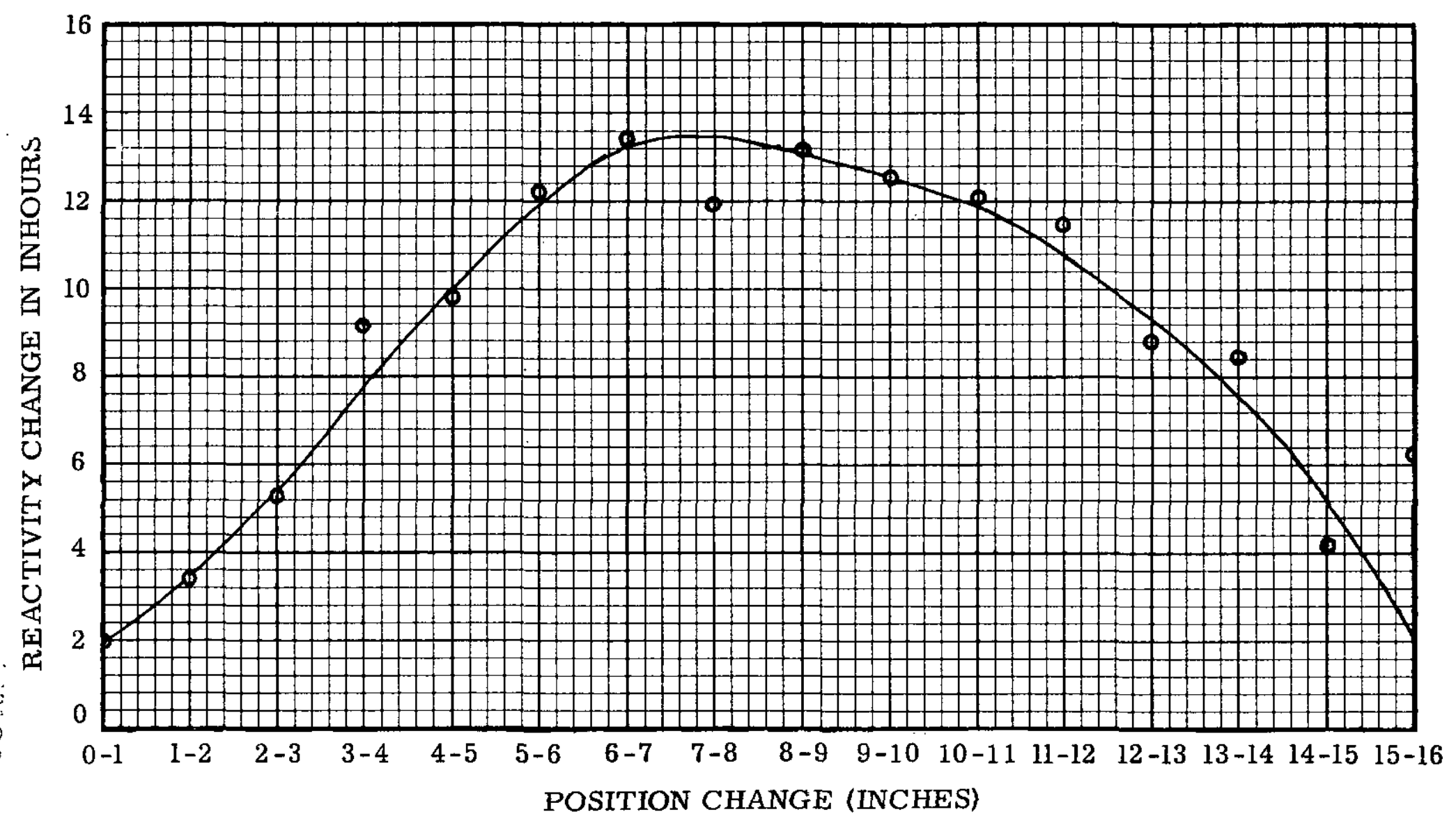

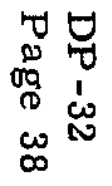




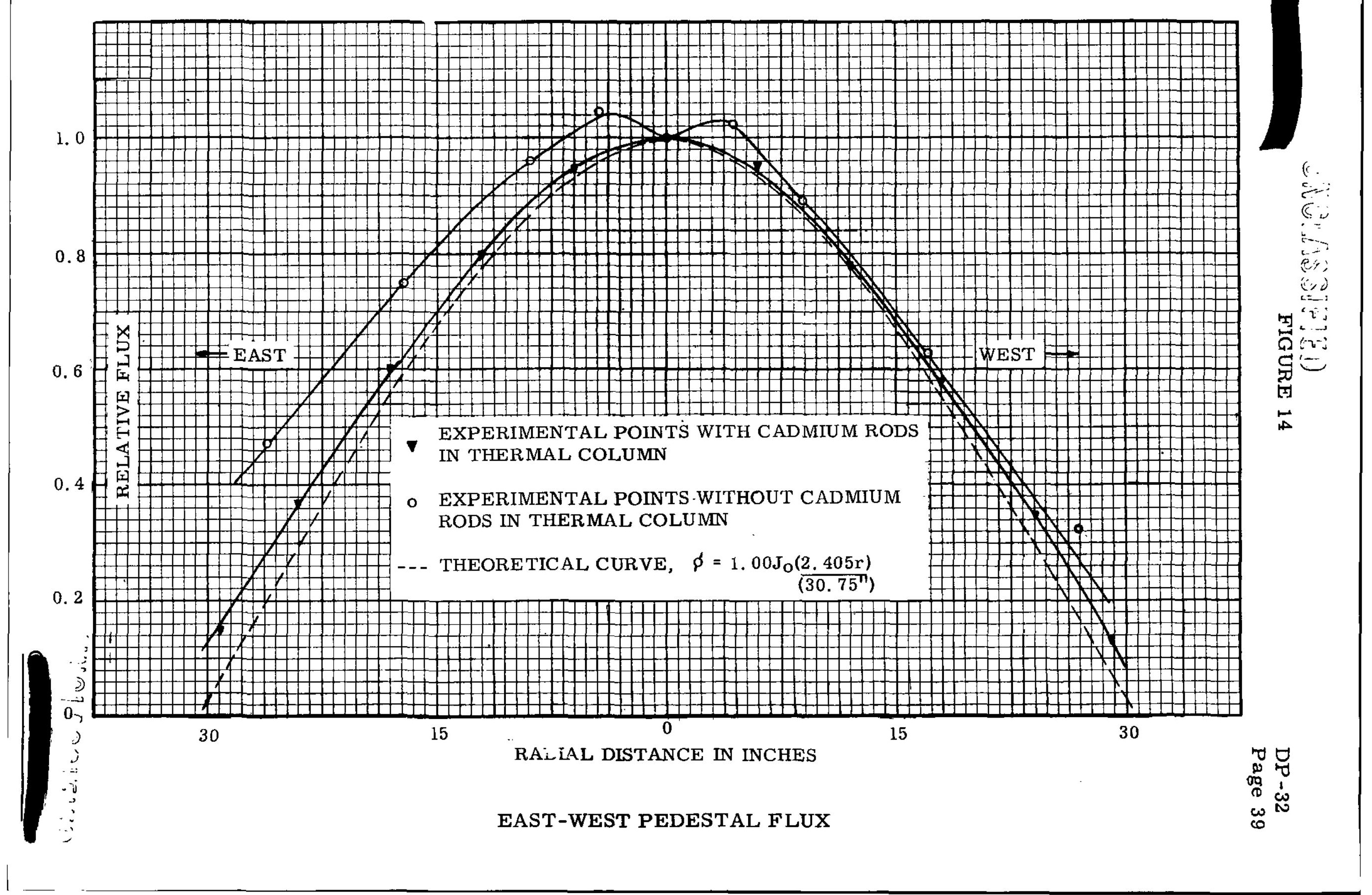



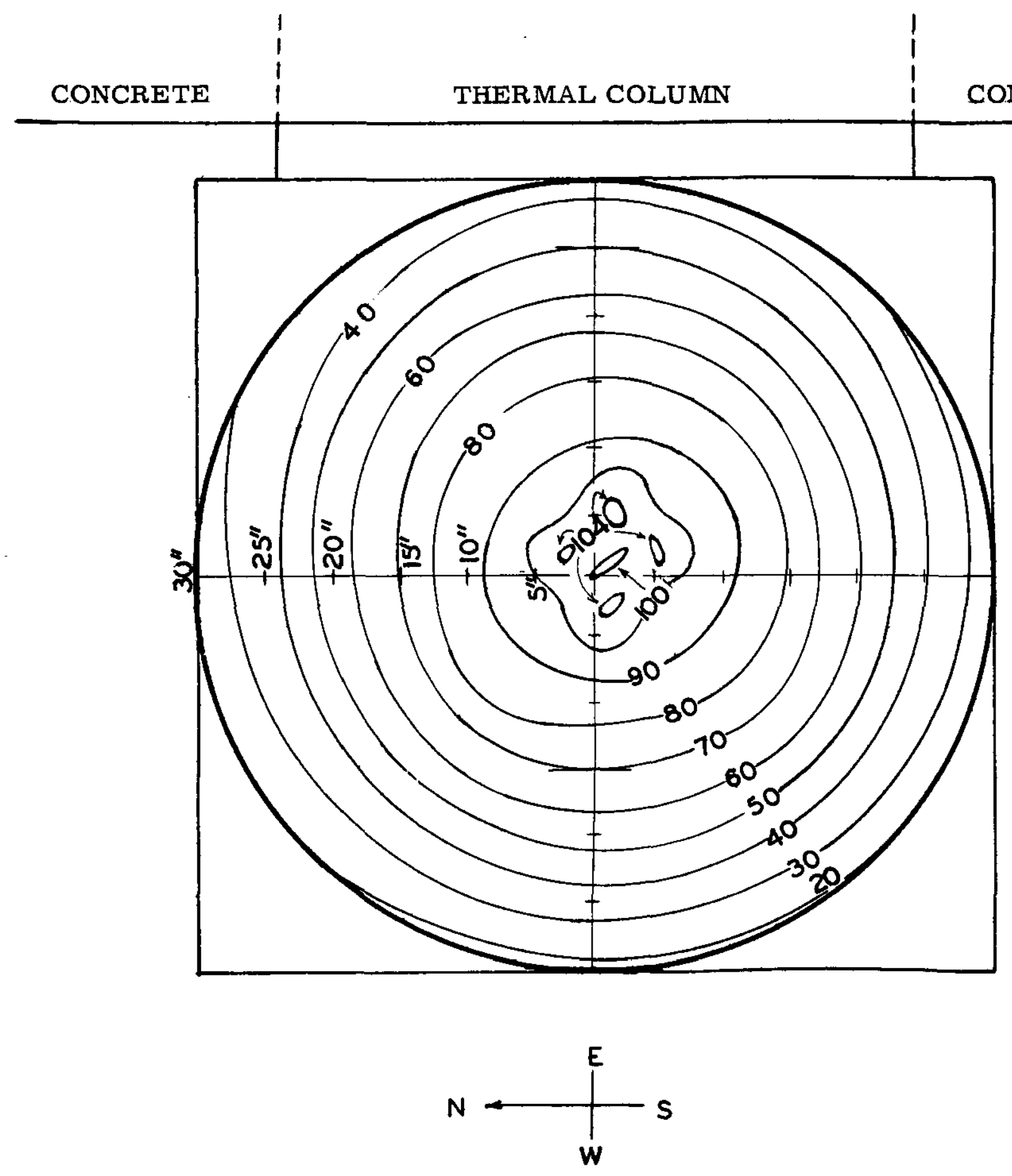

ISOFLUX PLOT OF THE PEDESTAL BEFORE ADDITION OF CADMIUM RODS TO THE THERMAL COLUMN 


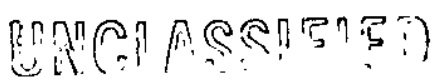

FIGURE 16

DP - 32

Page 41

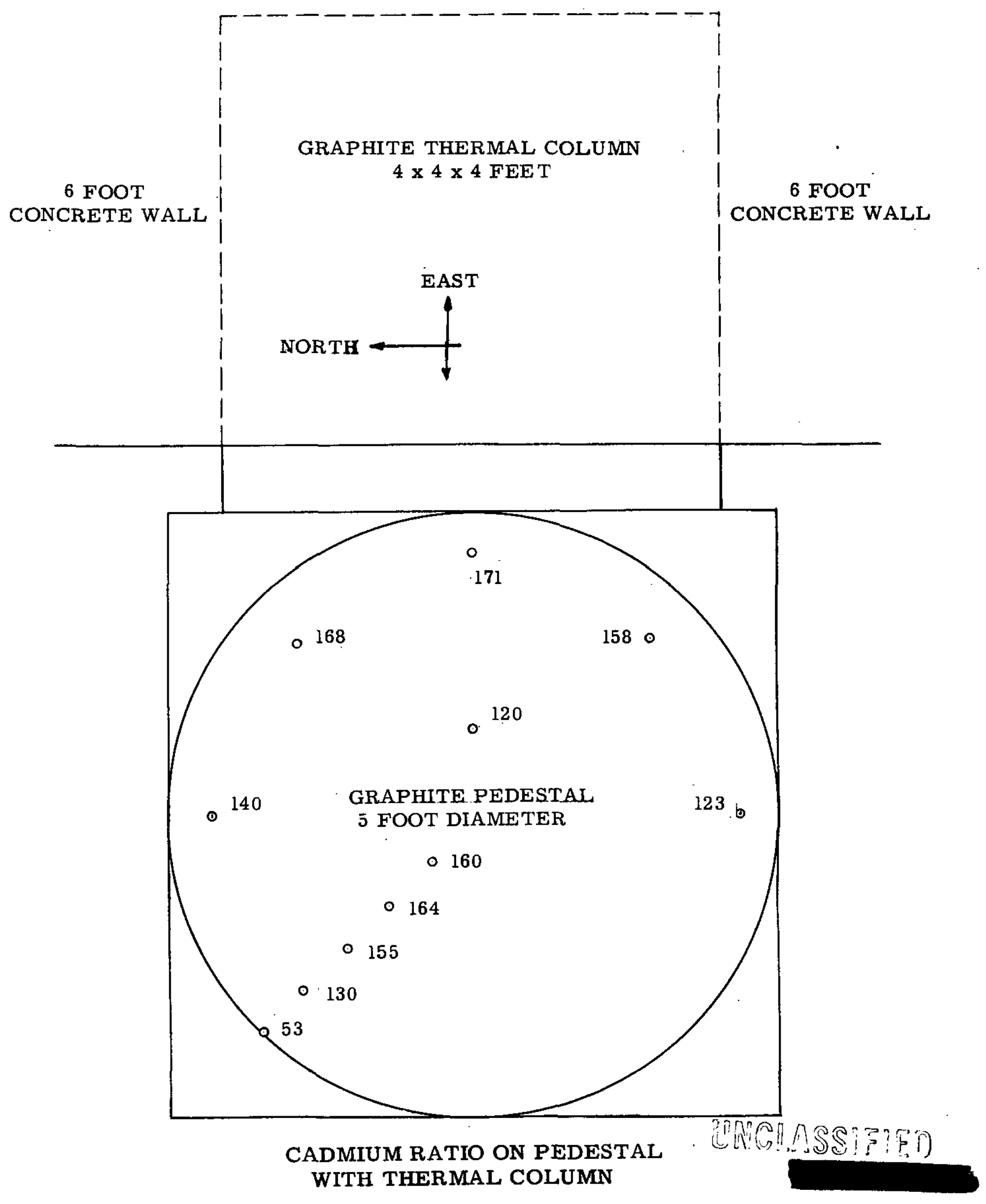




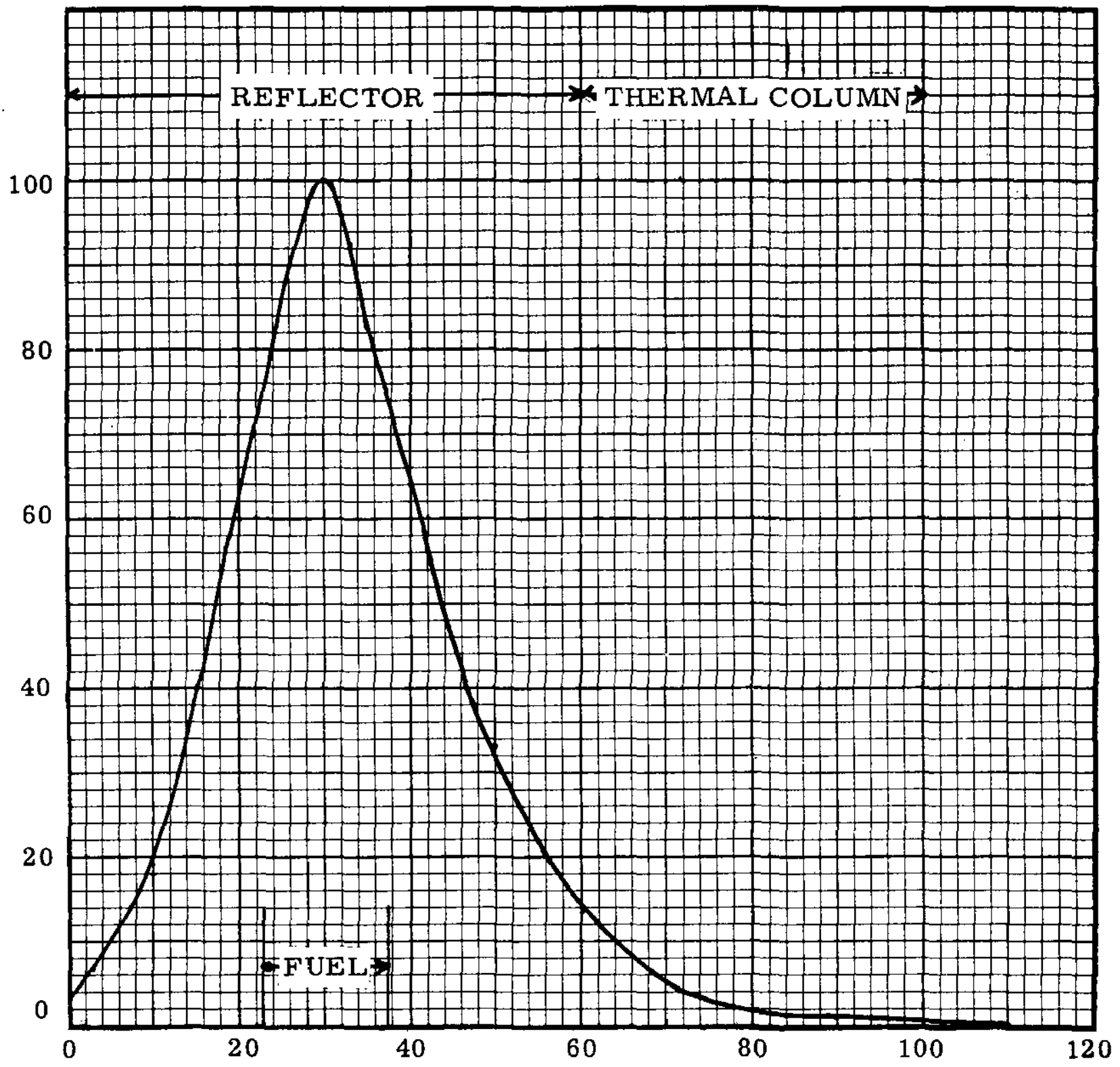

RELATIVE NEUTRON FLUX THROUGH CENTRAL THIMBLE WITH THERMAL COLUMN 
DESLIFIED

$\rightarrow$

FIGURE 18

DP -32

Page 43

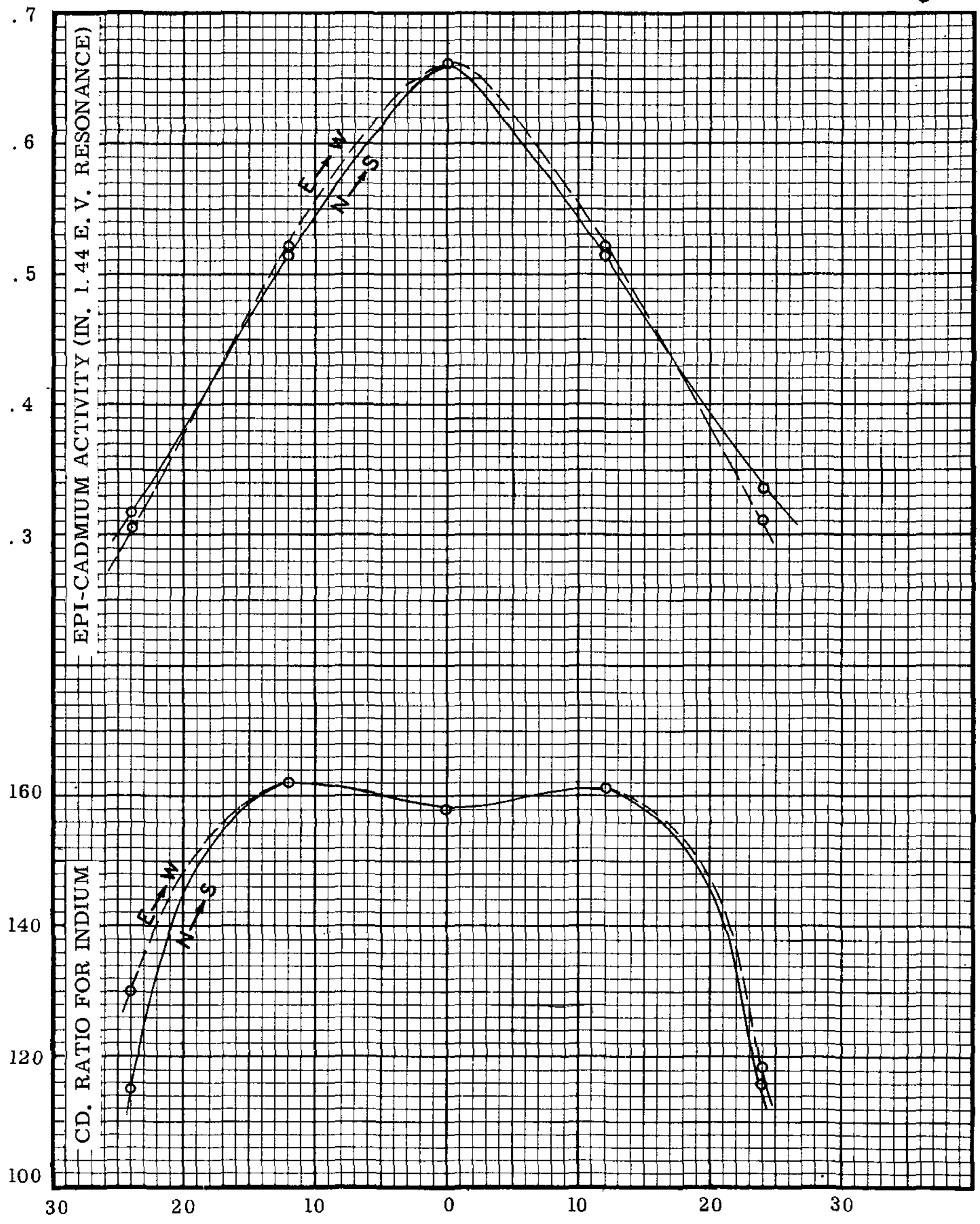

RADIAL DIS'TANCE - INCHES FROM CENTER ALONG N-S, E-W, DIAMETERS PEDESTAL FLUX WITH CADMIUM RODS IN THERMAL COLUMN 